\title{
GESTÃO DO INVESTIMENTO EM EFICIÊNCIA ENERGÉTICA EM CLIENTES INDUSTRIAIS COM O USO DA METODOLOGIA MULTICRITÉRIO DE APOIO À DECISÃO - CONSTRUTIVISTA
}

\section{INVESTMENT MANAGEMENT IN ENERGY EFFICIENCY IN INDUSTRIAL CUSTOMERS USING THE METHODOLOGY MULTICRITERIA DECISION AID - CONSTRUCTIVIST}

\author{
Sandra Rolim Ensslin ${ }^{1}$; Leonardo Ensslin ${ }^{2}$; Eduardo Kazumi Yamakawa ${ }^{3}$; Marilda da Penha \\ Teixeira Nagaoka ${ }^{4}$; Gustavo Klinguelfus ${ }^{5}$; Luciano Cavalcante Siebert ${ }^{6}$; Alexandre Rasi Aoki ${ }^{7}$ \\ ${ }^{1}$ Universidade Federal de Santa Catarina- UFSC - Florianópolis - Brasil \\ sensslin@gmail.com \\ ${ }^{2}$ Universidade Federal de Santa Catarina- UFSC - Florianópolis - Brasil \\ leonardoensslin@terra.com.br \\ ${ }^{3}$ Universidade Federal de Santa Catarina- UFSC - Florianópolis - Brasil \\ eduardo_yamakawa@uol.com.br \\ ${ }^{4}$ Universidade Federal de Santa Catarina- UFSC - Florianópolis - Brasil \\ marildanagaoka@yahoo.com.br \\ ${ }^{5}$ Universidade Federal do Paraná - UFPR - Curitiba - Brasil \\ gustavo.k@gmail.com \\ ${ }^{6}$ Universidade Federal do Paraná- UFPR - Curitiba - Brasil \\ siebert.luciano@gmail.com \\ ${ }^{7}$ Universidade Federal do Paraná- UFPR - Curitiba - Brasil \\ araoki@gmail.com
}

\begin{abstract}
Resumo
O objetivo do presente trabalho consiste em construir um modelo para avaliar o desempenho do processo de gestão do investimento em eficiência energética em clientes industriais. Trata-se de um estudo de caso, caracterizando-se como exploratório de natureza prática. Segue uma abordagem quali-quantitativa, tendo como instrumentos para a coleta de dados entrevistas semi-estruturadas com o Gestor de Projetos responsável pelo processo de gestão de investimento. $O$ instrumento de intervenção utilizado foi a metodologia MCDA-C. A metodologia permitiu identificar, organizar, mensurar e integrar os critérios. O modelo construído permite ao gerente visualizar o processo nos critérios por ele identificados como relevantes para o sucesso de sua gestão. O trabalho ilustra para o grupo de clientes industriais: o perfil de impacto; o resultado numérico de sua avaliação; o processo disponibilizado pelo modelo para gerar alternativas para aperfeiçoar o desempenho do processo e permitir ao gerente compreender as consequências destas ações. Como resultado do trabalho foram identificadas cinco ações que, segundo a percepção dos autores permitirão elevar o desempenho dos dois Ponto de Vista Elementares (PVEs) Edital e Clientes Alvo, que possuem o maior potencial de melhorias, permitindo uma elevação da performance do desempenho do Ponto de Vista Fundamental (PVF) Clientes da ordem de +27 para +52 .
\end{abstract}

Palavras-chave: avaliação de desempenho, apoio a decisão, eficiência energética, indústrias. 


\section{Introdução}

A eficiência no uso da energia entrou na agenda mundial a partir dos choques no preço do petróleo dos anos 1970, quando ficou claro que o uso das reservas de recursos fósseis teria custos crescentes, seja do ponto de vista econômico, seja do ponto de vista ambiental. Logo se reconheceu que um mesmo serviço poderia ser obtido com menor gasto de energia e, consequentemente com menores impactos econômicos, ambientais, sociais e culturais (EPE, 2010).

O desenvolvimento econômico do Brasil tem como uma de suas consequências naturais o aumento do consumo de energia elétrica nos setores residencial, comercial e industrial. Para suprir as novas demandas por energia elétrica para os próximos anos faz-se necessário realizar investimentos na ampliação do sistema de geração, transmissão e distribuição de energia elétrica. Além dos investimentos em infraestrutura, outra importante área é a eficiência energética que tem como foco a redução do desperdício de energia (MCLEAN-CONNER, 2009). Conforme (US National Policy Development Group, 2001), eficiência energética é a capacidade de utilizar menos energia para produzir a mesma quantidade de iluminação, aquecimento, transporte e outros serviços baseados na energia. Para ilustrar a importância destes programas, estudos internacionais têm mostrado que cada dólar investido em eficiência energética economiza dois dólares em sistemas de geração e distribuição energética (IEA, 2006).

Devido a importância da eficiência energética para o Brasil criou-se a Lei $\mathrm{n}^{\circ} 9991$ de 24/07/2000 e o Decreto $n^{\circ} 3867 / 2001$ que a regulamenta, que tratam dos investimentos a serem realizados em pesquisa e desenvolvimento do setor elétrico e em eficiência energética no uso final por parte das empresas concessionárias, permissionárias e autorizadas do setor de energia elétrica. De acordo com essa Lei, as empresas devem aplicar, no mínimo, 1\% da renda operacional líquida em projetos de eficiência energética, sendo, no mínimo, 0,50\% de sua receita operacional líquida em pesquisa e desenvolvimento do setor elétrico e 0,50\% em programas de eficiência energética no uso final de energia até o ano de 2006 quando estes percentuais se modificaram para $0,75 \%$ para P\&D e 0,25\% para eficiência energética no uso final.

O setor industrial é um dos principais pontos para direcionar esforços em eficiência energética, pois em 2004 este setor foi responsável por 47,9\% do consumo de eletricidade, sendo o setor residencial responsável por 21,9 \% e o comercial por 13,9\% (MME, 2005). Além disto, no setor industrial os sistemas motrizes consomem a maior parte da energia elétrica e apresentam o maior potencial de conservação de energia (MME/FDTE, 2005)

A inexistência de modelos científicos que explicitem os critérios utilizados para realizar a gestão do investimento da verba destinada a projetos de eficiência energética para clientes industriais por parte das concessionárias de energia elétrica, expõe as concessionárias à ocorrência de problemas com relação a destinar esta verba aos projetos com maior potencial de eficientização 
energética e que a mesma seja integralmente destinada aos projetos para que não haja incidência de multa por parte da Aneel nem questionamento quanto aos critérios de seleção dos projetos, que pode prejudicar a imagem da empresa perante os clientes. Estão presentes nessa situação múltiplos critérios não claramente conhecidos.

Nesse contexto, emerge a pergunta da pesquisa: quais os critérios a serem considerados no processo gestão do investimento em eficiência energética em clientes industriais, em um modelo que se propõe a apoiar o gerenciamento desses recursos de tal forma a promover a competitividade organizacional?

Com vistas a responder à pergunta de pesquisa proposta pelos autores, o objetivo do presente trabalho - de caráter exploratório - consiste em construir um modelo para avaliar a gestão do investimento em eficiência energética em clientes industriais, de tal maneira a permitir o aprimoramento do processo gestão dos investimentos do programa de eficiência energética em uma concessionária de energia elétrica.

Tendo em vista a ausência de modelos multicritérios para avaliar o desempenho de processos de investimentos em projetos de eficiência energética, que explicitem o processo de estruturação dos valores e preferências de um decisor particular, os objetivos específicos deste trabalho de pesquisa são:

1. Explicitar os atores do contexto e em particular o decisor em nome de quem os valores e preferências serão determinados;

2. Identificar os critérios que o decisor considera necessários e suficientes para avaliar o processo de gestão de investimentos em eficiência energética em clientes industriais;

3. Construir escalas ordinais e cardinais para mensurar tais critérios, segundo a percepção do decisor;

4. Integrar os critérios via taxas de compensação, conforme a percepção do decisor;

5. Ilustrar o entendimento gerado pela evidenciação do perfil de impacto dos critérios;

6. Evidenciar o processo de avaliação do processo;

7. Evidenciar o processo de geração de ações de aperfeiçoamento para o processo, visando mostrar as consequências das mesmas nos critérios.

O presente artigo descreve um estudo de caso no qual foi desenvolvido um modelo personalizado para um Gestor de Projetos de uma grande concessionária de energia elétrica com atuação no Brasil. Com a construção de um modelo de avaliação de desempenho baseado nos critérios julgados importantes pelo decisor, ele passou a dispor de um instrumento de apoio à decisão para a gestão do investimento em eficiência energética em clientes industriais. No desenvolvimento de tal modelo, utilizou-se a Metodologia Multicritério de Apoio à Decisão - 
Construtivista (MCDA-C), por seu diferencial em relação às metodologias MCDA tradicionais para estruturar contextos.

A fonte de coleta dos dados é de natureza primária e secundária, pelo fato de os dados terem sido coletados diretamente junto ao gerente de projetos, via entrevistas não estruturadas, e junto a documentos internos da organização. A abordagem metodológica utilizada pode ser classificada como quali-quantitativa. Qualitativa na estruturação quando identifica os critérios, constrói as escalas ordinais e quando das Recomendações. Quantitativa quando transforma as escalas ordinais em cardinais e as integra. A lógica da pesquisa é mista, indutiva na etapa da Estruturação e dedutiva na Avaliação.

A relevância da pesquisa pode ser argumentada em termos das contribuições (i) teóricas; e (ii) gerenciais que ela pretende oferecer. Com relação a (i), a proposta teórico-metodológica tem por objetivo oferecer, para uma empresa específica, um procedimento sistematizado para o desenvolvimento das etapas de identificação, mensuração/avaliação e recomendações de aperfeiçoamento dos aspectos julgados pelo decisor como necessários e suficientes para se ter em conta no processo de gestão de investimentos em projetos de eficiência energética. Com relação a (ii), busca-se oferecer um instrumento que permita ao decisor desenvolver seu entendimento do contexto de forma a permitir-lhe explicitar seus valores (critérios) e preferências (funções de valor e taxas de compensação) e as consequências de suas decisões nos mesmos.

O presente artigo é organizado conforme explicado a seguir: seção 1, de caráter introdutório; seção 2, com o constructo teórico da gestão de investimentos em eficiência energética e Avaliação de Desempenho; seção 3, com a construção do modelo de avaliação de desempenho do Estudo de Caso, e seção 4, com as Considerações Finais.

\section{Constructo Teórico}

Esta seção se subdivide em duas partes. A primeira apresenta o conceito de eficiência energética adotado neste estudo e a nova visão requerida em seu processo de avaliação. A segunda parte contempla as origens e as diferenças entre a MCDA-C, instrumento de intervenção adotado neste trabalho, e a MCDA.

\subsection{Eficiências Energéticas e Avaliação de Desempenho}

O uso eficiente da energia elétrica ganhou força no Brasil após a crise de energia no ano de 2001, pois, a partir de então, se percebeu que as ações até o momento não estavam direcionadas para o consumo e sim para a oferta de energia (ORTEGA, 2006). Economizar energia custa muito menos do que importá-la, não polui o ambiente, gerando empregos e o desenvolvimento econômico local (LOVINS e SWISHER, 2003).Um dos maiores aspectos quando se trata de políticas de 
eficiência energética é a avaliação dos resultados atingidos, avaliação das metas, avaliação da situação relativa entre outros países (BOSSEBOEUF, 1997). Para isso são necessários os indicadores de eficiência energética.O uso não criterioso de indicadores de eficiência energética pode implicar em conclusões errôneas (PATTERSON, 2001). Por exemplo, o decréscimo de um indicador de eficiência pode muitas vezes não representar uma eficiência energética inferior, mas a automação de um sistema fabril.As concessionárias de energia elétrica, por força de Lei, devem investir um percentual do seu faturamento em projetos de eficiência energética no uso final. As concessionárias têm cumprido os requisitos mínimos exigidos pela regulação, priorizando projetos que lhes tragam benefícios (JANUZZI, 2000).

A criação de um mecanismo regulatório ou legislativo não foi suficiente para garantir que os recursos fossem canalizados para as prioridades da sociedade. Constata-se que, apesar das empresas obedecerem a legislação que obriga a aplicação de $1 \%$ da renda líquida em eficiência energética, houve muita dificuldade de se apontar sua real contribuição para minorar a crise de abastecimento enfrentada a partir de meados de 2001 (JANUZZI, 2001).

Emerge assim a questão: "Quais os critérios a serem considerados no processo gestão do investimento em eficiência energética em clientes industriais?”. Para responder a esta pergunta, necessita-se de um instrumento que permita avaliar o processo segundo a percepção de seu gestor (decisor). Autores como Skinner (1986), Roy (1993, 1996, 2005), Keeney (1992), Landry (1995), Bana e Costa et al(1999), Zimmermann (2000), Shenhar (2001), Steward (2005), Igarashi et al(2008), dentre outros, alertam para a necessidade de se considerar os valores individuais do(s) decisor(es) ao construir os modelos para avaliar o desempenho de sistemas organizacionais, em detrimento das metodologias que se valem de valores e preferências coletivas ou determinadas via métodos estatísticos, ou mesmo utilizadas com sucesso no passado. Em face dessa delimitação, para a estruturação do modelo de avaliação de desempenho, propõe-se como instrumento de intervenção a Metodologia Multicritério de Apoio à Decisão Construtivista (MCDA-C).

\subsection{A MCDA-C e as metodologias MCDA tradicionais}

A MCDA-C encontra suas mais remotas origens há mais de dois séculos. Contudo, sua consolidação como instrumento científico de gestão ocorre somente a partir da década de 1980 com os trabalhos de Roy (1996) e Landry (1995) ao definir os limites da objetividade para os processos de apoio à decisão, de Skinner (1986) e Keeney (1992) ao reconhecer que os atributos (objetivos, critérios) são específicos ao decisor em cada contexto, de Bana e Costa (1993) ao explicitar as convicções da MCDA, dentre outros.

A MCDA-C surge como uma ramificação da MCDA tradicional para apoiar os decisores em contextos complexos, conflituosos e incertos. Complexos por envolverem múltiplas variáveis 
qualitativas e quantitativas, parcialmente ou não explicitadas. Conflituosos por envolverem múltiplos atores com interesses não necessariamente alinhados e/ou com preocupações distintas do decisor que não tem interesse de confrontá-los, mesmo reconhecendo que estes estarão disputando os escassos recursos. Incertos por requererem o conhecimento de informações qualitativas e quantitativas que os decisores reconhecem não saber quais são, mas que desejam desenvolver este conhecimento para poder tomar decisões conscientes, fundamentadas e segundo seus valores e preferências (ENSSLIN et al, 2010).

Segundo Roy (1994, 1996, 2005) citado por Ensslin et al (2010) os pesquisadores em MCDA podem ser classificados em dois grupos: aqueles que assumem um posicionamento racionalista e aqueles que adotam o construtivismo como lógica de investigação. Adicione-se ainda que, mesmo entre os adeptos da visão construtivista, muitos têm dificuldades para operacionalizar a etapa de estruturação em uma forma que reconheça os limites da objetividade. Este contexto estimulou alguns autores, que em seus instrumentos de pesquisa contemplam e priorizam esta etapa, a designá-la por MCDA-C para enfatizar a diferença da lógica de pesquisa. O uso dessa designação pode ser verificado em Correa (1996); Bana e Costa et al (1999); Ensslin, Dutra \& Ensslin (2000); Ensslin, Longaray \& Mackness (2005); Sannemann et al (2006); Longaray et al (2006); Igarashi et al (2008), dentre outros.

A metodologia MCDA-C reconhece os limites da objetividade como proposto por Roy (1996, 2005), Bana e Costa (1993), Keeney (1992), Landry (1995), Zimmermann (2000), Ensslin, Dutra \& Ensslin (2000), Shenhar (2001) e, por meio do uso de instrumentos tais como entrevistas abertas, brainstorming não estruturados, grafos, mapas de relações meio-fim, modelos de otimização, etc., os operacionaliza. E, assim, segundo Ensslin et al (2010) desenvolve no decisor um coerente corpo de conhecimentos capaz de lhe permitir compreensão das consequências de suas decisões nos aspectos que ele (decisor) julga importantes, sem impor os racionalismos da objetividade, tão úteis na física e na matemática, porém dissociados dos contextos decisórios específicos em que os decisores:

- Necessitam de apoio para explicitar e mensurar seu(s) valor(es) e preferências;

- Desejam ter em conta seu(s) valor(es) e preferências, e não valor(es) e preferências genéricos;

- Desejam compreender e visualizar as consequências de suas decisões em seus objetivos (critérios);

- Desejam estabelecer as performances de referências em cada objetivo (critério) segundo sua percepção;

- Desejam compreender a contribuição de cada objetivo nos objetivos estratégicos; 
- Desejam valer-se da expansão do conhecimento propiciado pelo processo de apoio à decisão para identificar oportunidades de aperfeiçoamento.

Este conjunto de demandas faz com que a metodologia MCDA-C tenha como sua principal vocação o processo de desenvolver o conhecimento do decisor sobre o contexto. O processo de desenvolvimento do conhecimento do decisor é realizado na metodologia MCDA-C em forma sistêmica e sistemática em três grupos de atividades: Estruturação, Avaliação e Recomendações, conforme ilustrado na Figura 1. A etapa da Estruturação contribui ao identificar, organizar e mensurar ordinalmente as preocupações que o decisor considera necessárias e suficientes para a avaliação do contexto. A Avaliação é utilizada como um instrumento para melhorar o entendimento ao construir escalas cardinais e taxas de substituição para representar suas preferências locais e globais. E, finalmente, a etapa de Recomendações, que continua o processo de expansão de seu entendimento do contexto ao buscar compreender as consequências de suas possíveis decisões nos critérios representativos das dimensões por ele consideradas relevantes, assim como no contexto como um todo (ENSSLIN et al, 2010)

Tendo em vista as diferenças teóricas e práticas dos métodos MCDA tradicionais em suas mais diversas denominações (MCDA, AHP, MAUT, MAVT, SMART, etc.), a metodologia proposta foi denominada MCDA-C.

Figura 1 - Fases da MCDA-C

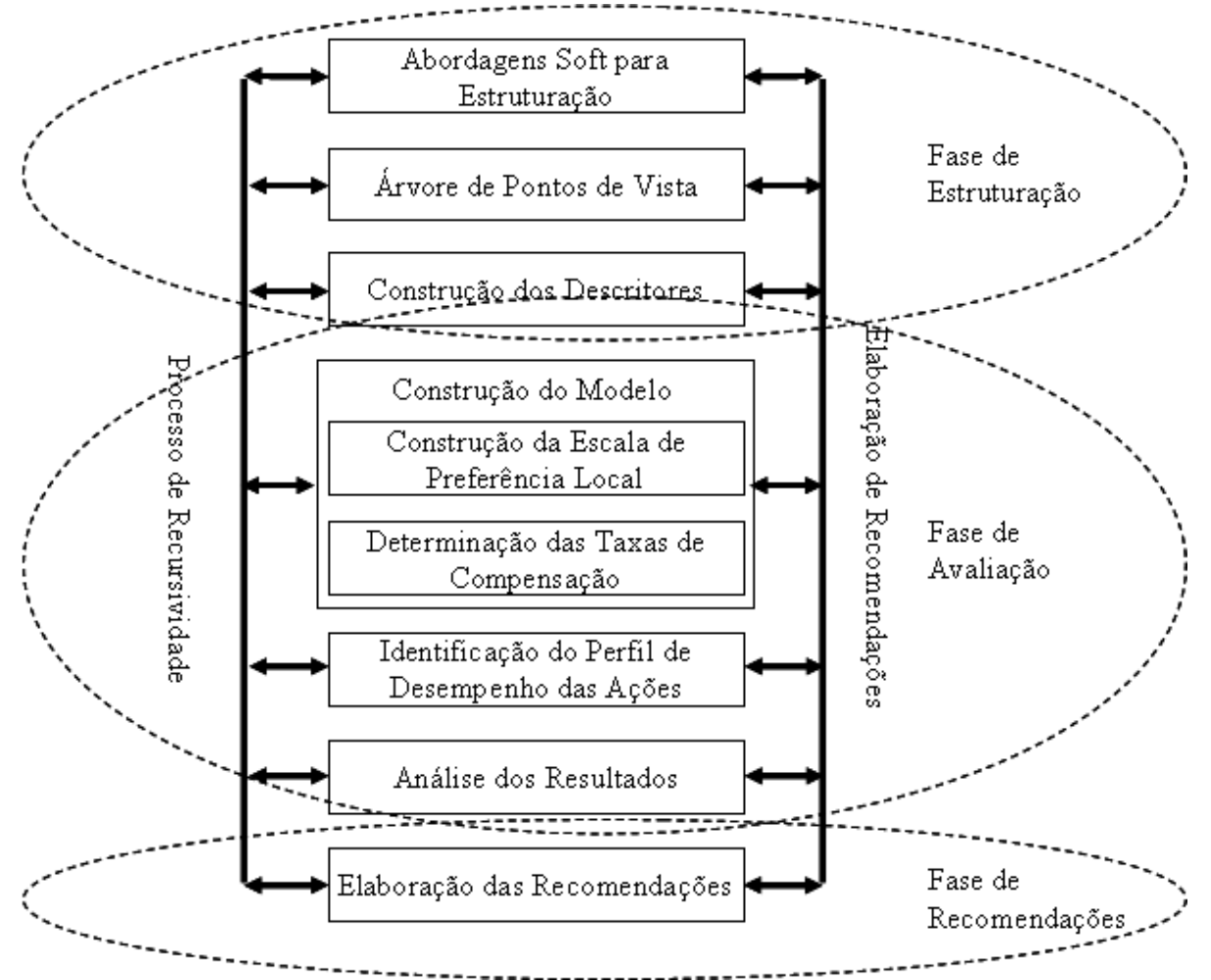

Fonte: Ensslin, Dutra e Ensslin (2000) 


\section{Construção do Modelo para Gestão de Investimentos em Eficiência Energética em Clientes}

Industriais

Em situações complexas, conflituosas e incertas como a do presente estudo, em que estão presentes a disputa de poder e a influência de diferentes atores, e que envolvem múltiplos e conflitantes critérios parcialmente conhecidos, metodologias do tipo multicritério que reconhecem os limites da objetividade emergem como o instrumento de intervenção recomendado (ROY, 1993; ROY e VANDERPOOTEN, 1996). A seleção da metodologia MCDA-C para auxiliar no processo de construção do modelo de gestão de investimentos em eficiência energética deve-se ao fato de ela partir da hipótese de que o gerenciamento é um processo contínuo materializado por meio de decisões para a implementação de ações de melhoria e ser um processo social que envolve indivíduos, valores, percepções, assim como relações de poder entre eles (ENSSLIN et al, 2010).

\subsection{Estruturação do Modelo}

Nessa fase, o contexto do problema é estruturado e organizado a partir dos aspectos julgados mais relevantes pelo decisor. É identificado o subsistema dos atores, fornecido um rótulo que represente o que se busca e identificados, organizados e mensurados ordinalmente os objetivos julgados pelos decisores como necessários e suficientes para avaliar o contexto, de acordo com seus valores e preferências.

\subsubsection{Contextualização, Subsistema de Atores e Rótulo}

O Estudo de Caso foi desenvolvido na filial de uma companhia distribuidora de energia elétrica do Brasil.

Neste contexto, situa-se a empresa do Estudo de Caso. A empresa pesquisada possui mais de 3,8 milhões de consumidores, sendo 74 mil consumidores industriais, em 393 municípios cerca de nove mil colaboradores. Na sua matriz está localizada a área de utilização de energia, que é responsável pelos projetos de eficiência energética.

Na primeira etapa do processo realizou-se a identificação de para quem seria feito o Apoio à Decisão, quem eram os atores com poder de interferência no processo e aqueles com interesse nas decisões a serem tomadas. O Quadro 1 representa o Subsistema de Atores envolvidos.

Quadro 1 - Subsistema de Atores

\begin{tabular}{|l|l|}
\hline Decisor & Gestor do projeto \\
\hline \multirow{3}{*}{ Intervenientes } & Aneel \\
\cline { 2 - 2 } & Diretoria de distribuição de energia elétrica \\
\cline { 2 - 2 } & Gerência de utilização de energia elétrica \\
\hline \multirow{2}{*}{ Agidos } & Clientes da empresa \\
\cline { 2 - 2 } & Sociedade \\
\hline
\end{tabular}

Fonte: Autores 
Posteriormente, por meio de um processo interativo entre os facilitadores e o decisor, foi elaborado um Rótulo o mais representativo possível quanto às principais preocupações do decisor em relação ao problema. O Rótulo do Estudo de Caso foi definido como: Construir um modelo para gestão do investimento em eficiência energética em clientes industriais.

\subsubsection{Elementos Primários de Avaliação, Conceitos e Áreas de Preocupação}

Para o levantamento dos dados relativos ao sistema de valores, foram realizadas entrevistas abertas com o decisor. Nas entrevistas, foi solicitado que o decisor discorresse a respeito do problema. Suas declarações foram analisadas para identificar os Elementos Primários de Avaliação (EPAs), que são as características ou propriedades do contexto que o decisor julga que impactam em seus valores. O maior número possível de EPAs deve ser identificado e novos podem surgir com a combinação dos pré-existentes. A análise das entrevistas permitiu a identificação inicial de 50 EPAs. Os 10 primeiros estão ilustrados no Quadro 2.

Quadro 2 - Os dez primeiros EPAs identificados

\begin{tabular}{|c|c|}
\hline EPA & Descrição \\
\hline 1 & Sistema que avalie a eficiência energética de empresas de diversos setores produtivos \\
\hline 2 & Multa por não fazer os investimentos em eficiência energética \\
\hline 3 & Boa imagem \\
\hline 4 & Indicadores de eficiência energética por setores produtivos \\
\hline 5 & Transparência na decisão \\
\hline 6 & Comparar desempenhos de diversos setores produtivos \\
\hline 7 & Utilidade para os clientes \\
\hline 8 & Reconhecimento pelos acionistas \\
\hline 9 & Metodologia abrangente \\
\hline 10 & Empresas sem fins lucrativos contemplados \\
\hline
\end{tabular}

Fonte: Autores

A partir dos EPAs, a metodologia MCDA-C recomenda expandir seu entendimento identificando a direção de preferência representada por cada um, assim como seu oposto psicológico para entender o grau mínimo de aceitabilidade do objetivo subjacente. Essa forma evolutiva de apresentar o EPA denomina-se conceito ou conceito orientado para a ação (ÉDEN e ACKERMANN, 1992). Sua obtenção é feita ao definir o objetivo subjacente ao EPA e, a seguir, ser solicitado ao decisor que fale a respeito do EPA, identificando: desempenho melhor possível; desempenho bom; desempenho ruim; desempenho pior possível (ainda aceitável) e a performance atual, bem como a intensidade que julga ser passar do intervalo pior possível ao intervalo melhor possível. Essa intensidade se reflete no verbo a ser utilizado na construção do conceito. O Quadro 3 
exibe os Conceitos para os 10 primeiros EPAs, onde a reticência (...) deve ser lida como "é preferível a" ou "ao invés de" e corresponde ao oposto psicológico (ENSSLIN et al, 2010).

Quadro 3 - Os dez primeiros Conceitos

\begin{tabular}{|c|l|}
\hline Conceito & \multicolumn{1}{|c|}{ Descrição } \\
\hline 1 & $\begin{array}{l}\text { Possuir um sistema que compare empresas de diversos setores produtivos... Não ter como } \\
\text { fazer a comparação }\end{array}$ \\
\hline 2 & Realização dos investimentos em sua totalidade... Pagar multa para Aneel \\
\hline 3 & Ter boa imagem com clientes... Reputação prejudicada \\
\hline 4 & $\begin{array}{l}\text { Ter indicadores de eficiência energética por setores produtivos... Não conseguir fazer } \\
\text { planejamento }\end{array}$ \\
\hline 5 & Ter transparência na decisão... Decisão ser contestada pelos clientes \\
\hline 6 & $\begin{array}{l}\text { Prover a comparação de desempenhos de diversos setores produtivos... Ficar sem dados } \\
\text { para comparar desempenhos }\end{array}$ \\
\hline 7 & Ter utilidade para os clientes... Clientes não irão aderir à pesquisa \\
\hline 8 & Ter reconhecimento pelos acionistas... Área perder prestígio e verbas \\
\hline 9 & Ter diversos tipos de clientes contemplados... Ter somente 1 tipo contemplado \\
\hline 10 & Ter empresas sem fins lucrativos contemplados... Ter somente indústrias contempladas \\
\hline
\end{tabular}

Fonte: Autores

Os conceitos que representam preocupações estratégicas equivalentes, segundo a percepção do decisor, podem ser agrupados em Áreas de Preocupação. Isto permite reunir os primeiros conceitos que explicam os valores do decisor e as propriedades do contexto que o mesmo tem em conta ao avaliar esta área (BANA e COSTA et al, 1999; ENSSLIN, DUTRA e ENSSLIN, 2000). Os nomes dados às áreas devem refletir da melhor forma possível a preocupação principal do decisor ao expressar os conceitos pertencentes ao agrupamento. Destaque-se, no entanto, que quem reflete o que é a área são os conceitos, e não o nome dado à mesma.

A Figura 2 mostra as Áreas de Preocupação do Estudo de Caso e a numeração dos respectivos conceitos que as compõem.

Figura 2 - Agrupamentos dos conceitos em Áreas de Preocupação

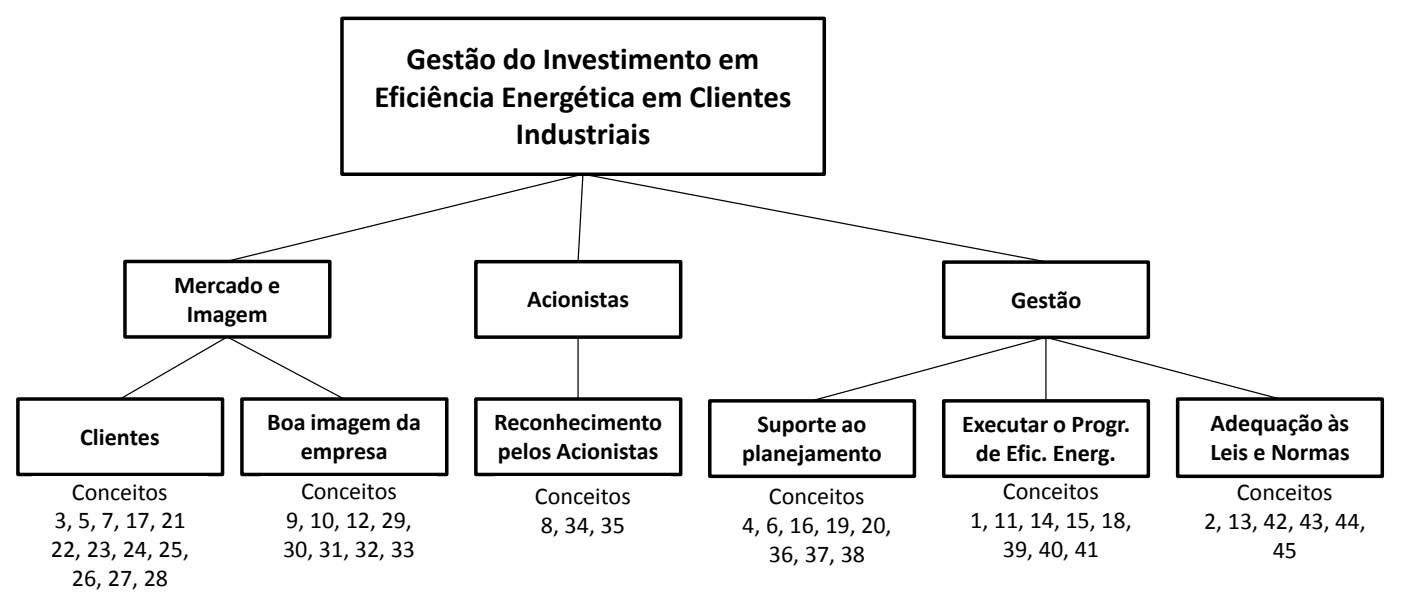

Fonte: Autores 


\subsubsection{Mapas Meios-Fins e Árvore de Pontos de Vista Fundamentais}

A partir dos conceitos geradores das áreas, a metodologia MCDA-C expande mais ainda o entendimento por meio da identificação das relações de hierarquia e das relações de influência entre os conceitos. Para tal, vale-se de mapas de relações meios-fins (BANA e COSTA et al, 1999; ENSSLIN, DUTRA e ENSSLIN, 2000). Sua construção se obtém solicitando ao decisor que discorra para cada conceito: "Como se pode obter o conceito fim?" e "Por que o conceito meio é importante?".

Para facilitar a análise e entendimento, o Mapa Meios-Fins é dividido em mapas menores formando os Clusters. Os Clusters são formados ao serem agrupados os ramos cuja argumentação reflita uma mesma preocupação do decisor e não existam relações de influência entre Clusters. Ao percorrer um ramo, o decisor segue uma linha de argumentação que conduz de um determinado conceito meio até o objetivo expresso pelo rótulo do problema. O nome de cada Cluster é dado em função do foco de interesse do decisor expresso pelos ramos que o compõem.

A Figura 3 ilustra o Mapa Meios-Fins para os Clusters Decisões e Utilidade. Os conceitos não numerados são os que emergiram no momento da construção do Mapa.

Figura 3 - Mapa Meios-Fins para os Clusters Decisões e Utilidade

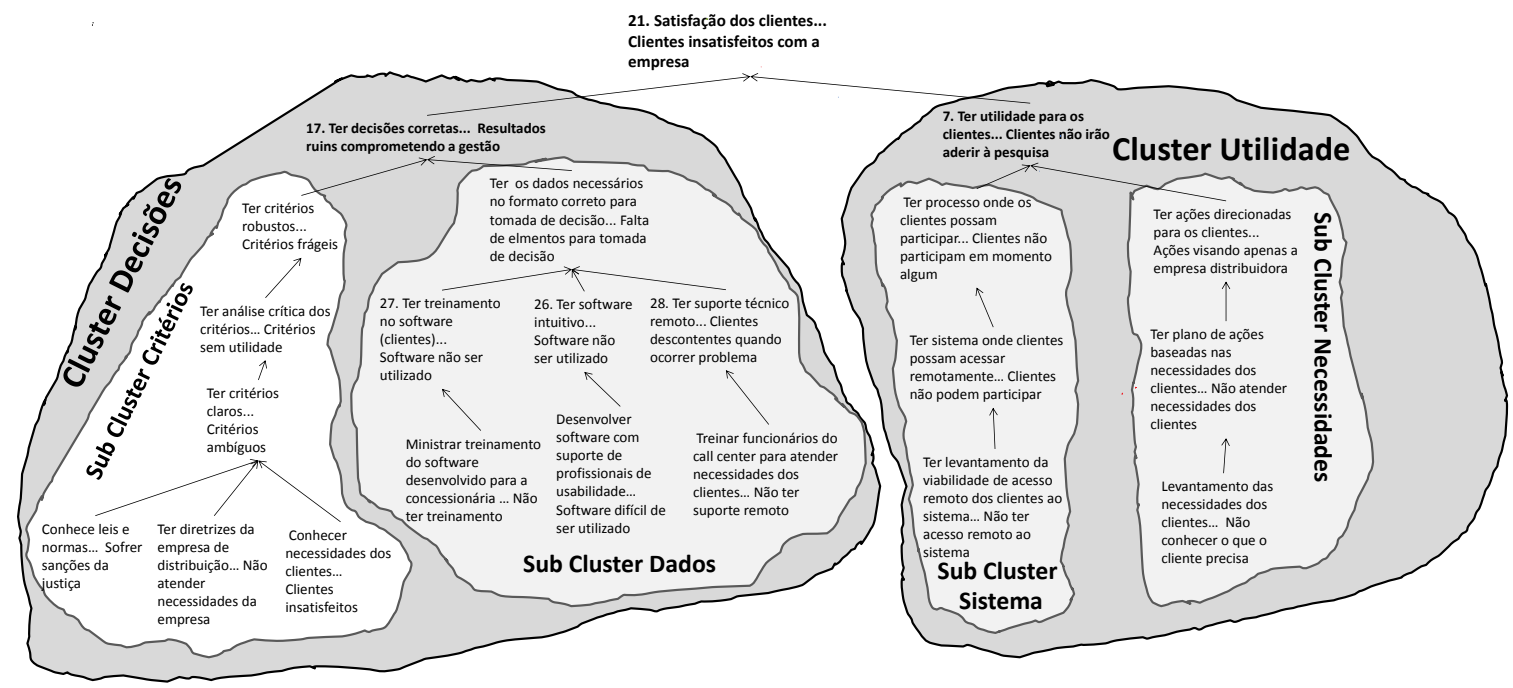

Fonte: Autores

Uma vez construídos todos os mapas, a metodologia MCDA-C propõe, para continuar seu processo de construir o entendimento, que a estrutura de relações de influência seja convertida em uma estrutura hierárquica de valor. Isto permite incorporar o entendimento dos julgamentos preferenciais do decisor no modelo em construção (KEENEY, 1992 apud ENSSLIN et al, 2010)

Uma preocupação a ser considerada é de que os Clusters iniciais devem ser testados para representarem aspectos do contexto de forma a ser: essencial, controlável, completo, mensurável, operacional, isolável, não-redundante, conciso e compreensível (KEENEY, 1992; ENSSLIN, 
MONTIBELLER e NORONHA, 2001; ROY, 2005, p. 10). Isto faz com que muitos Clusters iniciais tenham de ser desmembrados até que alcancem as propriedades acima. Uma vez atendidas estas propriedades, cada novo cluster, ao migrar para a estrutura hierárquica de valor, recebe a denominação de Ponto de Vista Fundamental (PVF).

À representação do Rótulo, Áreas de Preocupação e os respectivos Pontos de Vista Fundamentais dá-se o nome de Estrutura Hierárquica de Valor, conforme destacado na Figura 4 para o modelo construído para o Estudo de Caso.

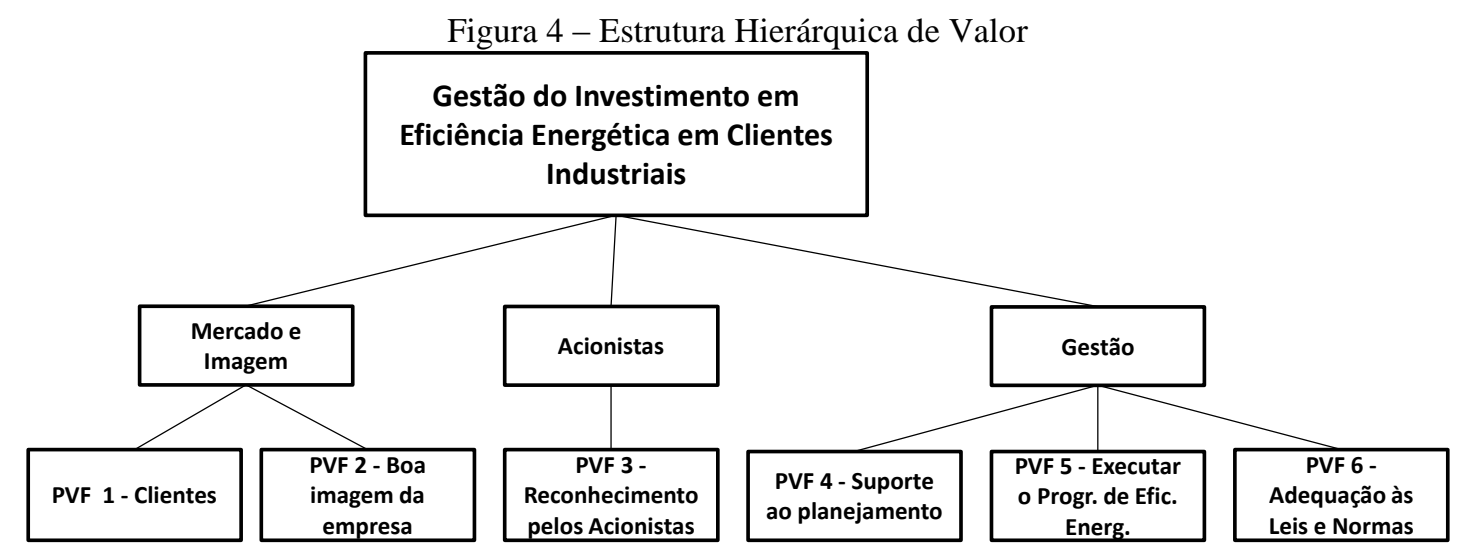

Fonte: Autores

\subsubsection{Estrutura Hierárquica de Valor e Descritores}

No entanto, os PVFs ainda são demasiado abrangentes para serem mensurados. Por isso, retorna-se aos Mapas Meios-Fins e analisam-se os subclusters. Tais subclusters devem obedecer às mesmas propriedades dos Clusters iniciais e seu processo de transformação é equivalente ao utilizados para os PVFs e estes subcritérios são denominados Pontos de Vista Elementares (PVEs). Este processo de decomposição continua até que se obtenha um PVE que represente uma propriedade do contexto e assim possa ser mensurado em forma objetiva, e não ambígua.

Uma vez construída a Estrutura Hierárquica de Valor, a metodologia MCDA-C propõe como passo seguinte a construção de escalas ordinais para mensurar os Pontos de Vista constituintes. A estas escalas ordinais denomina-se Descritor.

As escalas ordinais são construídas em um processo interativo com o decisor, que uma vez tenha construído a escala que melhor represente aquilo que ele julga relevante, identifica os Níveis de Referência, ou Âncoras, denominados Nível Bom, que representa o nível acima do qual o decisor julga a performance como excelente, e Nível Neutro, abaixo do qual o desempenho é comprometedor. Entre os dois pontos, o desempenho é competitivo (ROY, 2005).

A Figura 5 ilustra a Estrutura Hierárquica de Valor para o PVF Clientes, com os correspondentes PVEs e Descritores. 


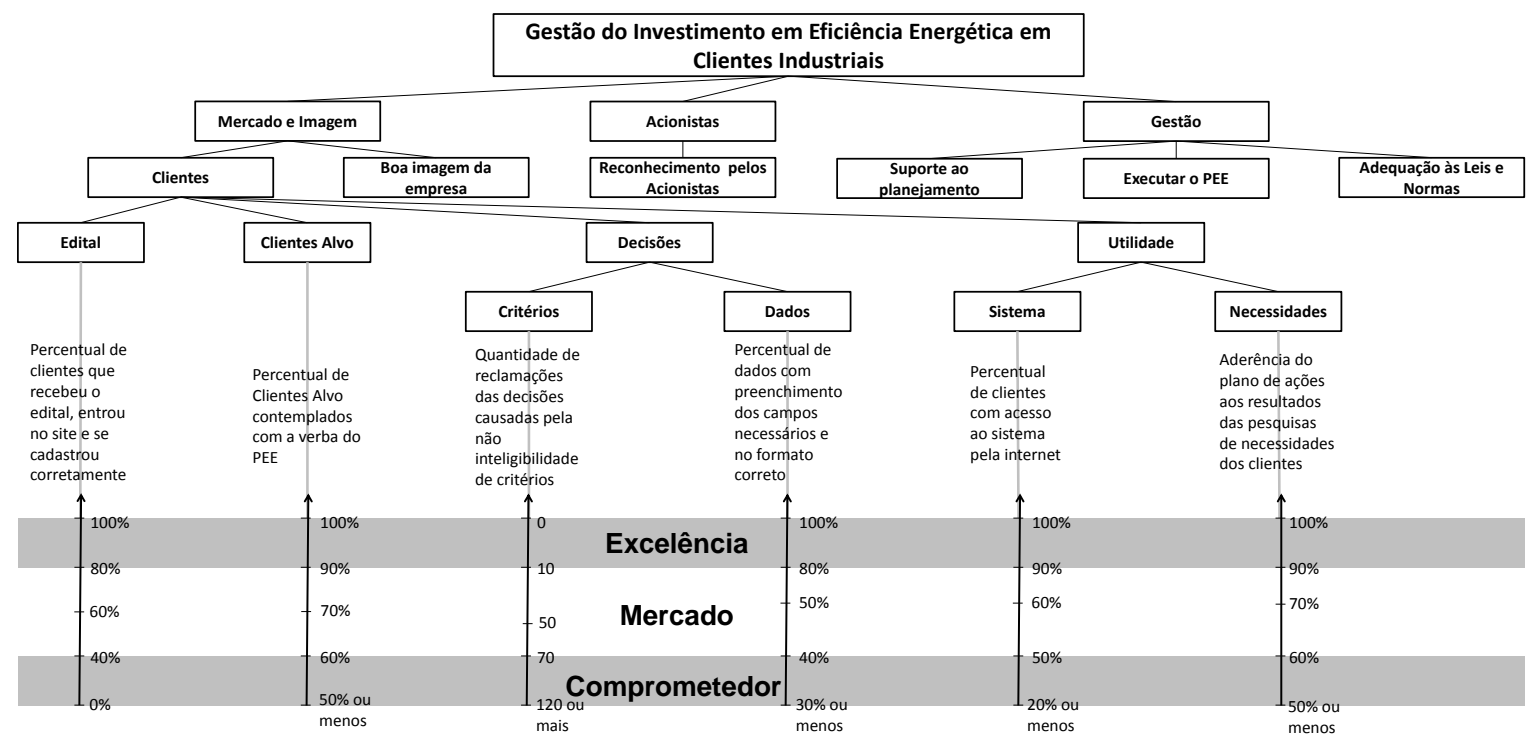

Fonte: Autores

Ao concluir a construção da Estrutura Hierárquica de Valor com os Descritores, desenvolveu-se todo o entendimento do contexto permitido por uma estrutura não numérica (escalas nominais e ordinais). Para continuar o processo de entendimento, devem ser incorporadas informações que possibilitem transformar as escalas ordinais em cardinais, que é o propósito da etapa seguinte da metodologia MCDA-C.

\subsection{Avaliação}

Ao concluir a etapa de estruturação, a metodologia MCDA-C terá construído um modelo contendo os aspectos julgados pelo(s) decisor(es) como necessários e suficientes para avaliar o contexto. As escalas neste modelo são ordinais e denominadas Descritores, conforme Figura 5. As referidas escalas muitas vezes se valem de símbolos numéricos para sua representação, estes, no entanto, são simplesmente símbolos alfa-numéricos, e não números do conjunto $\mathfrak{R}$ (conjunto dos números reais), para mais detalhes, ver Ensslin, Montibeller \& Noronha (2001), Barzilai (2001) e Azevedo (2001). É equivocado, portanto, utilizar estas escalas para qualquer função que envolva operações numéricas, pois elas não são numéricas. A MCDA-C reconhece as diferenças entre as escalas ordinais e cardinais e, para realizar a transformação, necessita mais uma vez a participação do decisor para fornecer informações que permitam conhecer a diferença de atratividade entre os níveis de cada escala. Esta atividade pode ser realizada por variados métodos, tais como: Pontuação Direta, Bissecção, MACBETH, dentre outras (ENSSLIN, MONTIBELLER e NORONHA, 2001). A MCDA-C vale-se de todos estes métodos para transformar as escalas ordinais em cardinais. O método MACBETH, por sua fundamentação teórica, representatividade e reconhecimento prático, tem sido o mais empregado, pelo que será o utilizado neste trabalho. 
Destaque-se que o Macbeth - Measuring Attractiveness by a Cathegorical Based Evaluation Technique é unicamente um método para transformar escalas ordinais em cardinais a partir de juízos absolutos sobre a diferença de atratividade entre duas alternativas, e não uma metodologia de apoio à decisão como AHP, MCDA, MAUT, MAVT, SMART, como pode ser evidenciado em Bana e Costa, De Corte \& Vansnick, (2005, p. 437): “The MACBETH approach and the MMACBETH software have been used to derive preference scales or value functions and scaling constants in many public and private applications of multicriteria additive value analysis, some of them reported in the literature".

\subsubsection{Funções de Valor}

Obtidos os Descritores de todos os pontos de vista, a metodologia MCDA-C, seguindo seu propósito de construir o entendimento do decisor, solicita a ele que informe a diferença de atratividade entre os níveis dos descritores (escalas ordinais). A partir destas informações, com a ajuda do software M-Macbeth, constroem-se escalas cardinais que atendam os juízos de preferências do decisor. Estas escalas denominam-se Funções de Valor.

O procedimento de uso do método MACBETH consiste em solicitar ao decisor que expresse a diferença de atratividade entre duas alternativas potenciais $\boldsymbol{a}$ e $\boldsymbol{b}$ ( $\boldsymbol{a}$ mais atrativa que $\boldsymbol{b}$ ) com base em uma escala ordinal de sete categorias semânticas propostas a priori ao decisor para cada intervalo do descritor (BANA e COSTA e VANSNICK, 1995). Os níveis de atratividade da escala semântica são: nula, muito fraca, fraca, moderada, forte, muito forte e extrema. Em seguida, são estabelecidos os Níveis de ancoragem Bom (100) e Neutro (0), transformando a escala em uma Escala de Intervalos Ancorada. Deste modo, os Níveis Âncora Bom e Neutro terão igual grau de atratividade para todos os descritores e igual pontuação numérica para todas as funções de valor.

Com base nas respostas do decisor, constrói-se a Matriz de Julgamentos, cujos valores servem de entrada para o software determinar a função de valor.

A Figura 6 apresenta o processo completo de transformação de um descritor (escala ordinal) em uma Função de Valor (escala cardinal): o descritor Clientes Alvo; a Matriz de Julgamento; a escala ancorada fornecida pelo software M-Macbeth e a Função de Valor, numérica e gráfica. 
Figura 6 - Transformação do Descritor Clientes Alvo em Função de Valor por meio do Método MACBETH

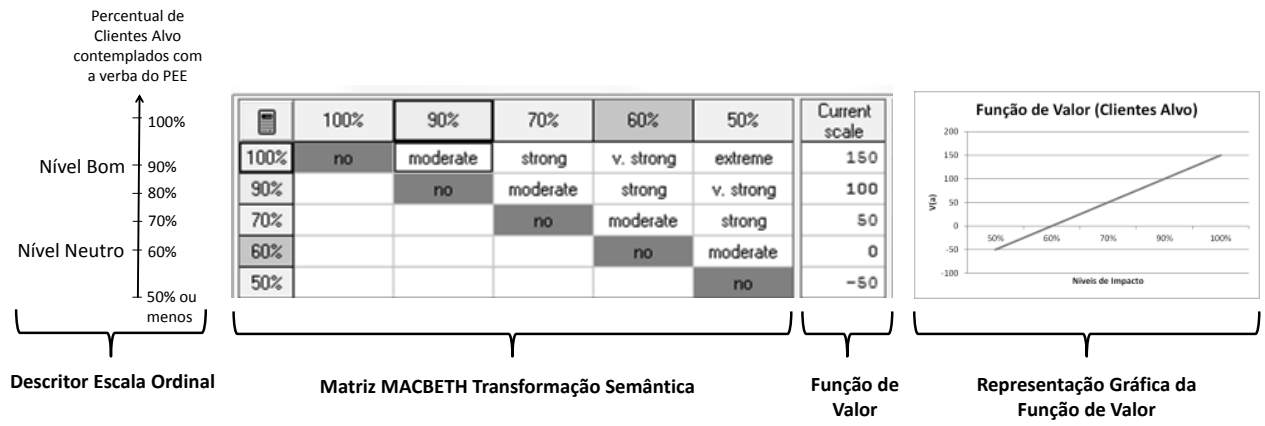

Fonte: Autores

A

Figura 7 apresenta o conjunto de escalas cardinais construídas para o PVF Clientes.

Figura 7 - Escalas cardinais do PVF Clientes

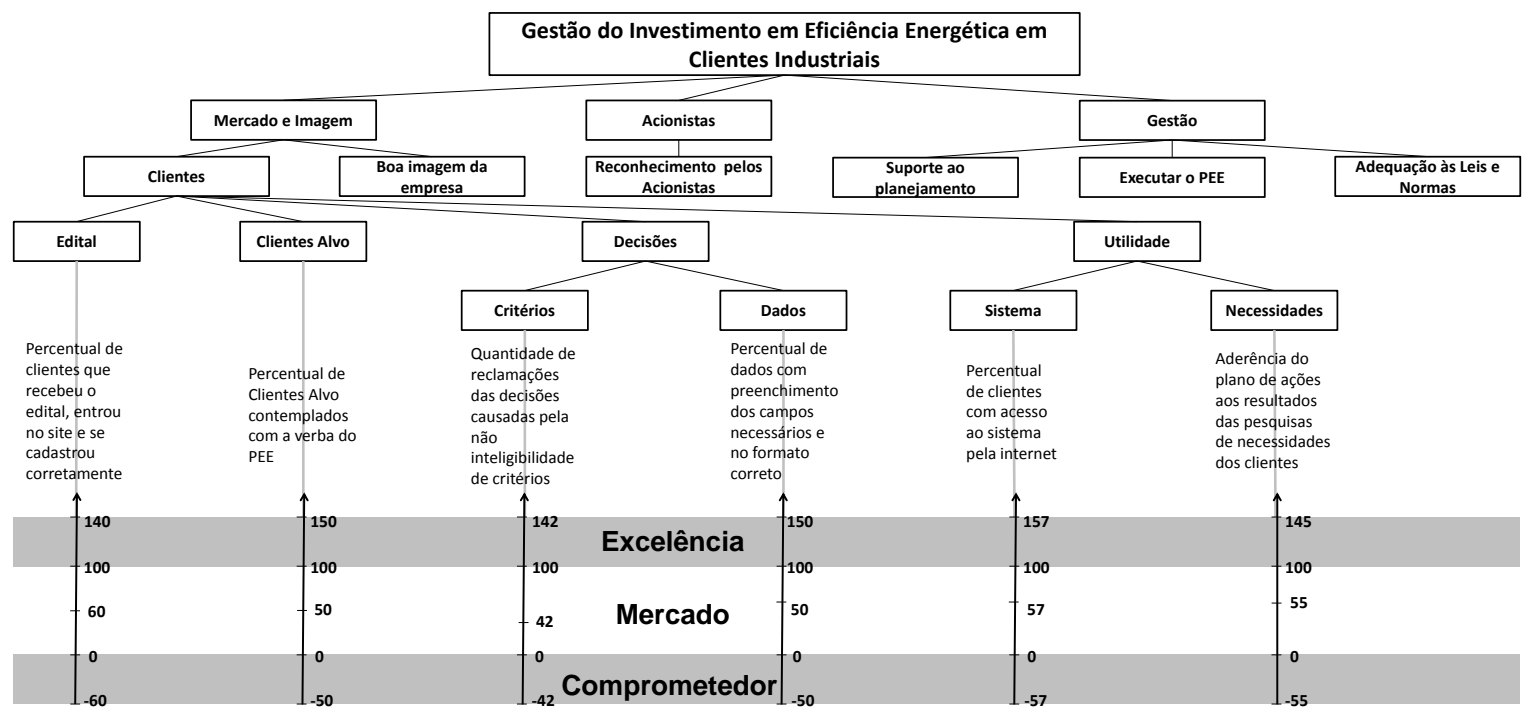

Fonte: Autores

Ao concluir a construção das funções de valor, a metodologia MCDA-C terá disponibilizado ao decisor um entendimento que lhe possibilita viabilizar a mensuração cardinal de cada aspecto operacional considerado relevante. Contudo, não lhe permitirá ainda visualizar a mensuração dos aspectos julgados estratégicos, os Pontos de Vista Fundamentais, e nem os táticos, os Pontos de Vista Elementares intermediários. Para dar prosseguimento ao processo de construção do entendimento, devem ser incorporadas informações que permitam integrar as escalas cardinais. Este é o propósito da etapa seguinte da metodologia MCDA-C.

\subsubsection{Taxas de Substituição}

A etapa seguinte na construção do entendimento consiste em agregar as avaliações locais de cada critério em uma avaliação global do processo de gestão de investimentos em eficiência energética. $\mathrm{O}$ entendimento se materializa na explicitação do modelo geral de avaliação que irá 
permitir mensurar a performance do processo de gestão. A integração é realizada por meio das Taxas de Substituição, ou de Compensação. O método utilizado foi o de Comparação Par-a-Par do MACBETH, por não necessitar que o decisor expresse seus julgamentos de valor por meios numéricos, mas sim semânticos.

O processo tem início com a identificação da estrutura hierárquica que se deseja integrar por meio da definição das taxas que representam o juízo de valor preferencial do decisor, seja a estrutura hierárquica a representada em destaque na

Figura 8. Isto é, deseja-se determinar as taxas para os PVEs Critérios e Dados.

Figura 8 - Estrutura Hierárquica de Valor com destaque para os PVEs Critérios e Dados

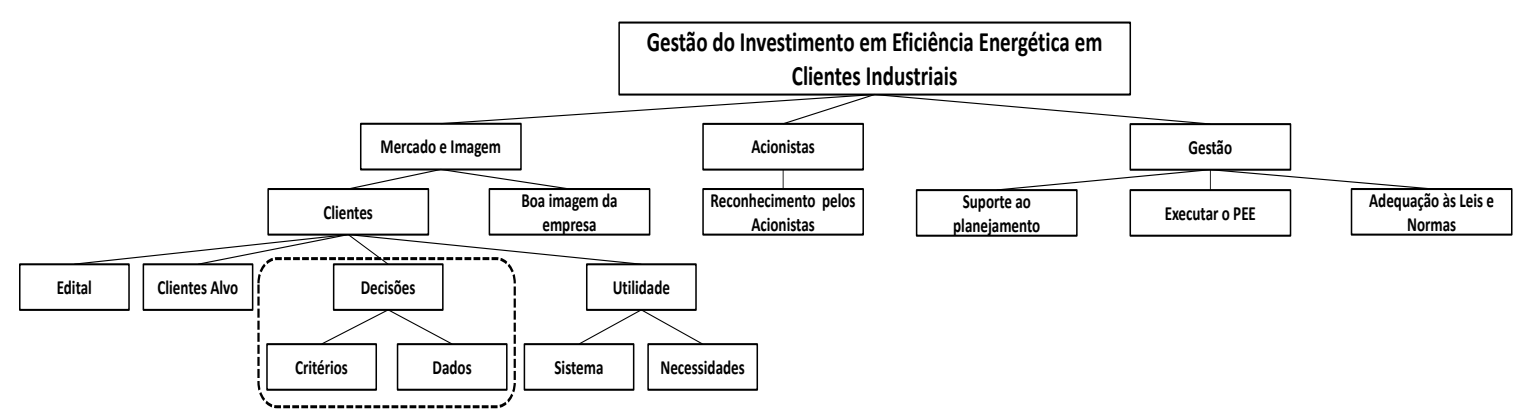

Fonte: Autores

Inicialmente, é necessário criar ações potenciais que representem a contribuição da passagem do nível Neutro para o nível Bom, em cada um dos critérios que se deseja determinar as taxas, assim como uma ação de referência com desempenho Neutro em todos os pontos de vista, conforme apresentado na Figura 9.

Figura 9 - Alternativas potenciais para determinar as taxas de substituição com a indicação dos respectivos níveis Bom e Neutro

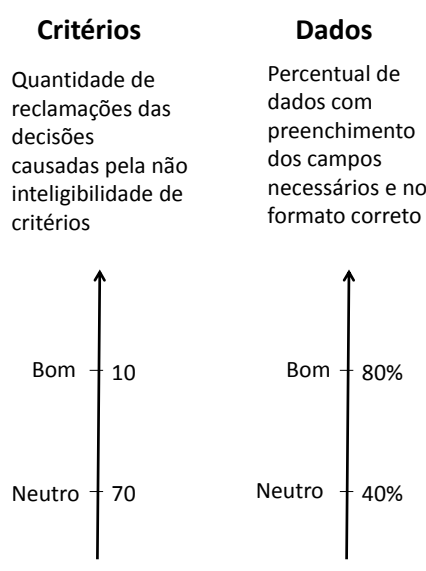


A1

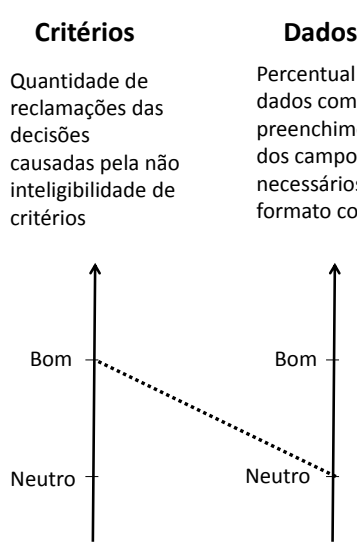

A2

\begin{tabular}{ll}
\multicolumn{1}{c}{ Critérios } & \multicolumn{1}{c}{ Dados } \\
Quantidade de & $\begin{array}{l}\text { Percentual de } \\
\text { dados com } \\
\text { reclamações das }\end{array}$ \\
preenchimento \\
causadas pela não & dos campos \\
inteligibilidade de & necessários e no \\
critérios & formato correto
\end{tabular}

\begin{tabular}{|c|c|}
\hline \multicolumn{2}{|c|}{ AO } \\
\hline Critérios & Dados \\
\hline $\begin{array}{l}\text { Quantidade de } \\
\text { reclamações das } \\
\text { decisões } \\
\text { causadas pela não } \\
\text { inteligibilidade de } \\
\text { critérios }\end{array}$ & $\begin{array}{l}\text { Percentual de } \\
\text { dados com } \\
\text { preenchimento } \\
\text { dos campos } \\
\text { necessários e no } \\
\text { formato correto }\end{array}$ \\
\hline
\end{tabular}

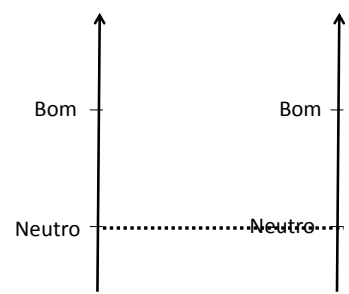

Fonte: Autores

A seguir, ordenam-se as alternativas, o que pode ser realizado utilizando-se a Matriz de Roberts, conforme apresentado no Quadro 4. Para isso, o decisor deverá fornecer as informações sobre as alternativas potenciais construídas segundo seu juízo preferencial. Sempre que preferir a alternativa da linha, marca-se na coluna com a qual está comparando o valor 1, em caso contrário, zero. Ao final somam-se os valores das linhas e se obtém o grau de preferência conforme o valor da soma. Gera-se, desta forma, a hierarquização das alternativas, cuja ordem reflete a preferência do decisor para passar do nível Neutro para o nível Bom em cada PVE.

Quadro 4 - Matriz de Roberts da comparação dos PVEs Critérios e Dados

\begin{tabular}{|c|c|c|c|c|c|}
\hline & A1 & A2 & A0 & Soma & Ordem \\
\hline A1 & & 1 & 1 & 2 & 1 \\
\hline A2 & 0 & & 1 & 1 & 2 \\
\hline A0 & 0 & 0 & & 0 & 3 \\
\hline
\end{tabular}

Fonte: Autores

As alternativas ordenadas são agora inseridas no software M-Macbeth, que se valendo da mesma lógica anterior fornece as Taxas de Substituição, como pode ser observado na Figura 10.

Figura 10 - Taxas de substituição calculadas pelo M-Macbeth para os PVEs Critérios e Dados

\begin{tabular}{|c|c|c|c|}
\hline & A1 & A2 & A0 \\
\hline A1 & & forte & forte \\
\hline A2 & & & forte \\
\hline A0 & & & \\
\hline
\end{tabular}

\begin{tabular}{|c|}
\hline Escala Atual \\
\hline 60 \\
\hline 40 \\
\hline 0 \\
\hline
\end{tabular}

Fonte: Autores

Processo similar é realizado com todas as estruturas hierárquicas. A Figura 11 ilustra a as Taxas de Substituição do modelo construído, para o Ponto de Vista Fundamental Clientes segundo os níveis de referência estabelecidos pelo Gestor de Projetos. 
Figura 11 -Taxas de Substituição para o modelo construído para o PVF Clientes

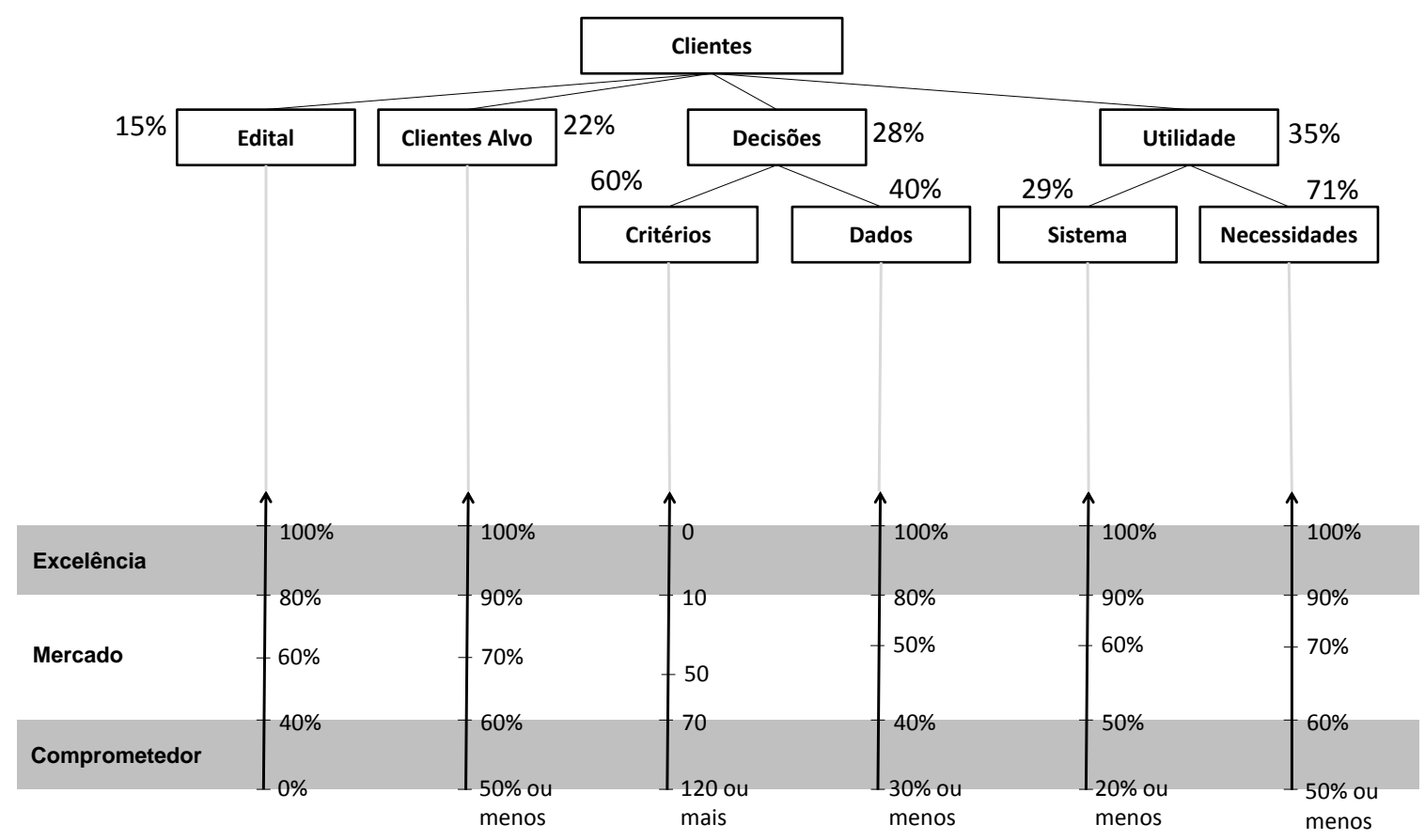

Fonte: Autores

\subsubsection{Avaliação Global e Perfil de Impacto da Situação Atual}

Para o PVF clientes, a equação do modelo é:

$$
\begin{array}{r}
V(a)=0,15 \cdot V_{P V F \text { Edital }}(a)+0,22 \cdot V_{P V F \text { ClientesAlvo }}(a)+0,60 \cdot 0,28 \cdot V_{\text {PVF Critérios }}+0,40 \cdot \\
\cdot 0,28 \cdot V_{P V F \text { Dados }}+0,29 \cdot 0,35 \cdot V_{\text {PVF Sistema }}+0,71 \cdot 0,35 \cdot V_{\text {PVF Necessidades }}
\end{array}
$$

Assim, a forma genérica é dada pela Equação (2).

$$
V_{P V F_{k}}(a)=\sum_{i=1}^{n_{k}} w_{i, k} \bullet v_{i, k}(a)
$$

Em que:

$V_{P V F_{k}}(a)$ : valor global da ação $a$ do $\mathrm{PVF}_{\mathrm{k}}$, para $\mathrm{k}=1, \ldots \mathrm{m}$;

$v_{i, k}(a)$ : valor parcial da ação $a$ no critério $\mathrm{i}, \mathrm{i}=1, \ldots \mathrm{n}$, do $\mathrm{PVF}_{\mathrm{k}}$, para $\mathrm{k}=1, \ldots \mathrm{m}$;

$a$ : nível de impacto da ação $a$;

$w_{i, k}$ : taxas de substituição do critério $\mathrm{i}, \mathrm{i}=1, \ldots \mathrm{n}$, do $\mathrm{PVF}_{\mathrm{k}}$, para $\mathrm{k}=1, \ldots \mathrm{m}$;

$\mathrm{n}_{\mathrm{k}}$ : número de critérios do $\mathrm{PVF}_{\mathrm{k}}$, para $\mathrm{k}=1, \ldots \mathrm{m}$;

m: número de PVFs do modelo.

Pode-se, a partir desse momento, utilizar o modelo para apoiar o processo de gestão, o que é realizado com o suporte do modelo de avaliação para o PVF Clientes. O modelo ajuda a entender o grau de alinhamento dos PVEs com os objetivos estratégicos do Gestor de Projetos. Para ilustrar o 
estudo de caso, o decisor apresentou a pontuação do status quo que pode ser observado na Figura 12.

Figura 12 - Perfil de Impacto do status quo do programa de eficiência energética

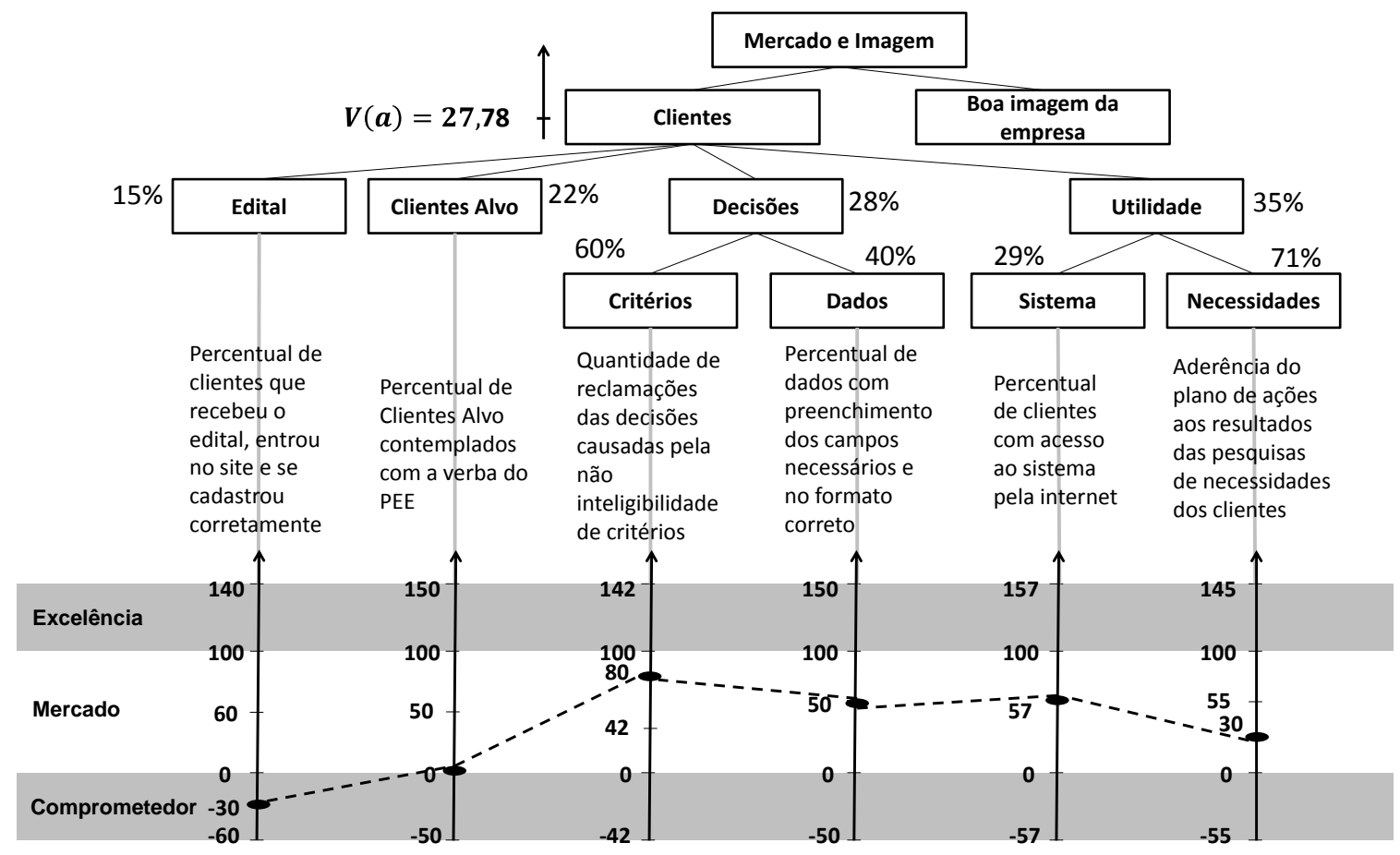

Fonte: Autores

Como pode ser verificado, os principais pontos de aperfeiçoamento estão nos PVEs Edital e Clientes Alvo. O modelo, ao ser construído segundo os valores e preferências do Gestor, permitiu visualizar o impacto do programa de eficiência energética naquilo que o Gestor (decisor) considera relevante. Este entendimento o ajuda a identificar os locais específicos onde atuar. Agora, com o entendimento de onde é conveniente atuar, o Gestor necessita identificar ações e avaliar o impacto das mesmas para o alcance dos objetivos estratégicos. Na metodologia MCDA-C esta etapa é denominada Recomendações.

\subsection{Recomendações}

A etapa de Recomendações na metodologia MCDA-C tem por função servir de apoio ao decisor para ajudá-lo a identificar formas para melhorar o desempenho do objeto que está sendo avaliado, assim como entender as conseqüências destas ações nos objetivos estratégicos do decisor, caso venham a ser implementadas. Como pode ser observado, esta etapa não possui um caráter prescritivo para informar o que fazer, mas sim um caráter de apoio para ajudar a construir ações e compreender suas conseqüências (ENSSLIN et al, 2010).

Seguindo esta filosofia de trabalho, e restringindo o processo de recomendações para a empresa que está em seu período de avaliação para homologação, o Gestor pode vinculá-la ao aperfeiçoamento de alguns critérios com desempenho atual em níveis comprometedores. 
Esta etapa inicia identificando os PVEs onde se deseja aperfeiçoar o desempenho. Para o presente caso, os PVEs foram: Edital e Clientes Alvo. Ilustra-se o processo para estes PVEs. Para entender as origens do desempenho da candidata neste PVF, visualiza-se o perfil de impacto da empresa candidata nos PVEs onde se situam as evidências da performance. Como pode ser visto na Figura 13, os PVEs Edital e Clientes Alvo são aqueles onde o desempenho se situa em níveis mais comprometedores, logo, os principais candidatos a serem aperfeiçoados.

Para Tasca (2010) a geração de recomendações tem por base os critérios que, na concepção dos decisores, estejam com desempenho abaixo de suas expectativas. Sempre que possível os decisores devem ser orientados a estabelecer prioridades e buscar ações na seguinte ordem:

(i) Objetivos com maior contribuição;

(ii) Objetivos com desempenho baixo; ou

(iii) Ambos (maior potencial de contribuição).

Figura 13 - Perfil de Impacto dos PVEs no status quo e com a aplicação das ações de melhoria

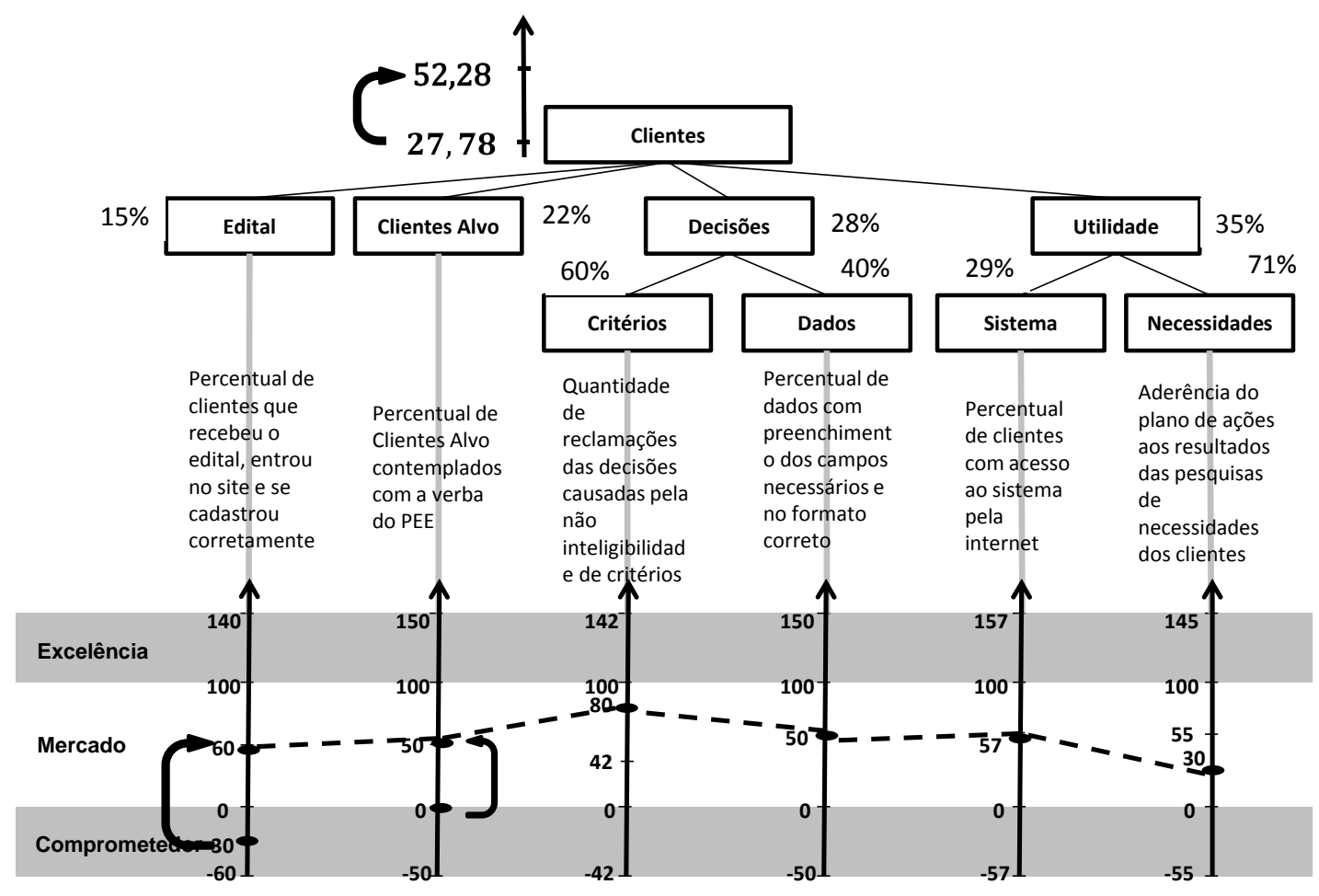

Fonte: Autores

O processo consiste em visualizar o descritor e o correspondente status quo do nível de impacto da empresa sendo avaliada. A partir dessa informação, buscam-se com os atores envolvidos alternativos para fazer com que o impacto no PVE apresente uma melhora. Para ilustrar o processo, tome-se como exemplo o descritor do PVE - Edital conforme Figura 14. 
Figura 14 - Alteração na performance no Descritor do PVE - Edital com aplicação das Ações de Aperfeiçoamento

Descritor PVE

Edital

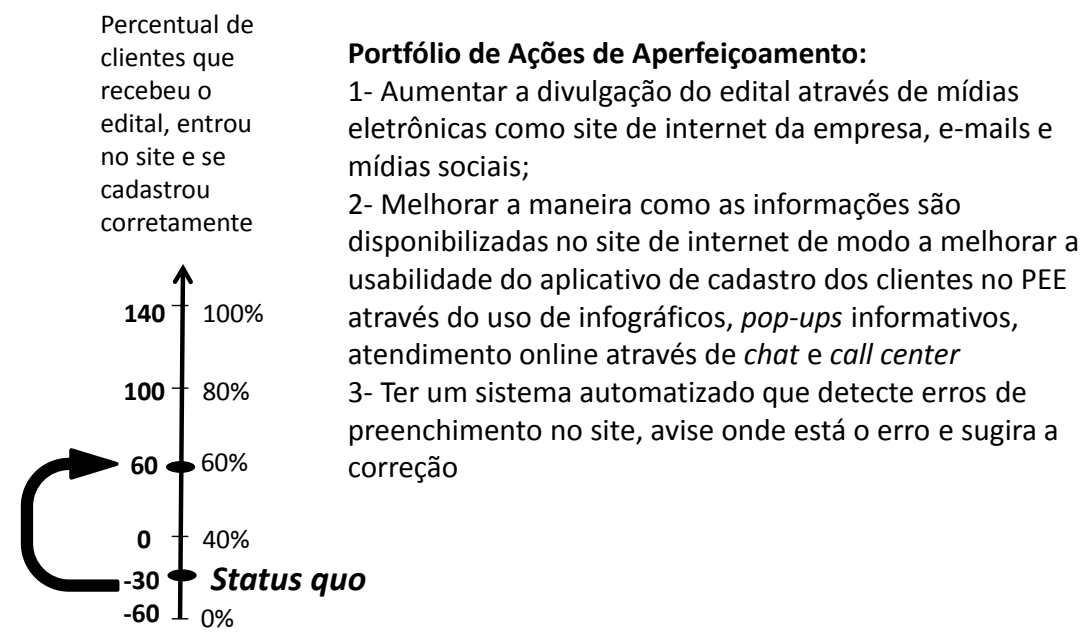

Fonte: Autores

Foram identificadas cinco ações que, segundo a percepção dos atores que as identificaram, permitirão elevar o desempenho do PVE - Edital de $20 \%$ de clientes para $50 \%$ de clientes que entram no site e se cadastram corretamente (ou de -30 para 60 na escala cardinal da Figura 14). Igual procedimento foi realizado com o PVE Clientes Alvo, fazendo com que o desempenho se elevasse aos valores apresentados no Perfil de Impacto da Figura 14. Este conjunto de ações, caso implementadas, elevaria a performance do $\mathrm{PVF}_{1}-$ Clientes de +27 para +52 .

Percebe-se, assim, que a etapa de Recomendações na metodologia MCDA-C fornece os meios para o decisor identificar:

- Onde é conveniente atuar;

- Processo para gerar ações para promover o aperfeiçoamento;

- A visualização das consequências da implementação.

Outros cenários podem igualmente ser desenvolvidos e testados. Esta é a função da etapa de Recomendações, ajudar a construir entendimento para que o decisor possa identificar os meios (ações) cujas consequências melhor atendam seus objetivos. Com isto, a metodologia MCDA-C em suas três fases: Estruturação, Avaliação e Recomendações; mantém seus pressupostos construtivistas.

\section{Considerações Finais}

O presente artigo objetivou construir um modelo para avaliar o desempenho do processo de gestão de investimentos em eficiência energética em clientes industriais. Por se tratar de um contexto complexo, com interesses conflitantes e onde os atores envolvidos não estavam seguros a 
respeito do que deveria ser tido em conta, foi utilizada a metodologia MCDA-C como instrumento de intervenção. O trabalho contemplou as etapas de Estruturação, Avaliação e Recomendações. As informações utilizadas para construir o modelo foram obtidas por meio de entrevistas com o Gestor de Projetos da concessionária de energia elétrica. O trabalho teve caráter exploratório na forma de estudo de caso, valendo-se de uma abordagem quali-quantitativa, e uma lógica de pesquisa mista, indutiva nas etapas de estruturação e recomendações e dedutiva na etapa de avaliação.

O objetivo geral da pesquisa consistiu em construir um modelo para gestão do investimento em eficiência energética em clientes industriais, de tal maneira a permitir o aprimoramento do processo de gestão dos recursos a serem destinados à indústrias para ações de eficiência energética. Este objetivo foi alcançado por meio da Equação 1, a qual foi operacionalizada pelos objetivos específicos propostos. O alcance do objetivo geral foi construído gradativamente com os objetivos específicos.

A metodologia MCDA-C trabalha com processos personalizados aos atores, contexto e momento, desta forma, o trabalho teve início com a contextualização e explicitação dos atores envolvidos, notadamente o decisor e os facilitadores, conforme apresentado na seção 3.1.1. Contextualização, Subsistema de Atores e Rótulo, atendendo assim ao objetivo específico 1.

O decisor, na seção 3.1.3. - Mapas Meios-Fins e Árvore de Pontos de Vista Fundamentais, explicitou que os critérios a serem tidos em conta são: 1- Clientes; 2- Boa Imagem da Empresa; 3Reconhecimento pelos Acionistas; 4- Suporte ao Planejamento; 5- Execução do Programa de Eficiência Energética; e 6- Adequação às Leis e Normas. Assim, atende-se ao objetivo específico 2 - Identificar os critérios que o decisor considera necessários e suficientes para avaliar os investimentos em eficiência energética em clientes industriais.

Para atender ao objetivo do trabalho de construir um modelo para avaliar o desempenho do processo de gestão do investimento em eficiência energética em clientes industriais, de tal maneira a permitir o aprimoramento do processo gestão dos investimentos em eficiência energética em clientes industriais, foi necessário mensurar o alcance de cada um dos critérios e integrá-los. A mensuração ordinal foi realizada na fase de estruturação e exibida na seção 3.1.4. Estrutura Hierárquica de Valor e Descritores. A Figura 5 apresenta a mensuração ordinal do critério PVF $_{1}-$ Clientes. As escalas construídas pelo decisor, nesta fase, foram alfa-numéricas, uma vez que não atendiam aos quesitos da unidade e da origem (zero representar ausência de medida) e, portanto, foram transformadas em escalas cardinais para admitirem operações numéricas. Esta transformação foi realizada na fase de avaliação mostrada na seção 3.2. Avaliação, e ilustrada para o descritor (escala ordinal) Clientes Alvo, na Figura 6. As Funções de Valor (escalas cardinais) para o PVF $_{1}-$ Clientes encontram-se na Figura 7, atendendo assim ao objetivo específico 3 - Construir escalas ordinais e cardinais para mensurar esses critérios, segundo a percepção do decisor. 
A integração foi realizada ainda na fase de Avaliação e apresentada na seção 3.2.2. Taxas de Substituição. O processo de integração foi ilustrado para os PVEs - Critérios e Dados, conforme apresentado na Figura 10. A integração global foi explicitada na seção 3.2.3. Avaliação Global e Perfil de Impacto da Situação Atual, por meio da equação 1 (Equação Global), atendendo integralmente o objetivo específico 4 - Integrar os critérios via taxas de compensação.

O objetivo específico 5 - Ilustrar o entendimento gerado pela evidenciação do perfil de impacto das ações, e o 6 - Evidenciar o processo de avaliação do processo, foram realizados na mesma seção 3.2.3, Figura 12.

O objetivo específico 7 - Evidenciar o processo de geração de ações de aperfeiçoamento, foi realizado na seção 3.3. Recomendações, em que foi analisado seu perfil e onde estão as oportunidades para melhorar seu desempenho. A partir de então, a metodologia MCDA-C mostrou como gerar ações de aperfeiçoamento e na Figura 13 suas consequências ao mostrar que a pontuação da mesma no $\mathrm{PVF}_{1}$ - Clientes mudaria de +27 para +52 se o portfólio de ações de aperfeiçoamento recomendadas fosse implementado. Com isto, a metodologia MCDA-C atendeu aos objetivos geral e específicos.

O modelo construído no Estudo de Caso foi legitimado pelo decisor em cada etapa de sua construção, e com sua utilização, o decisor e a concessionária de energia elétrica passaram a contar com um instrumento que oportuniza a melhoria contínua na gestão do investimento em eficiência energética em clientes industriais, aberto a ações criativas e inovadoras para a melhora do desempenho.

Dentre as contribuições do trabalho, destacam-se: no nível teórico, a evidenciação das diferenças entre a MCDA-C e a MCDA; no nível prático, a demonstração da potencialidade da metodologia MCDA-C para, em contextos onde o decisor não consegue explicitar o que leva em conta para decidir, construir, a partir da sua participação comprometida, os critérios que ele julga necessários e suficientes para avaliar o contexto.

Como limitação da pesquisa, ressalta-se o caráter de personalização da mesma, não recomendando a aplicação do modelo representado pela equação 1 em outros contextos, uma vez que o modelo foi construído segundo os valores e preferências de um decisor específico. Quanto ao processo proposto pela metodologia MCDA-C, as limitações principais são: requer a participação comprometida do decisor e o elevado tempo que o processo demanda.

\section{Abstract}

This paper aims to build an assessment model for the investment in energy efficiency in industrial customers process performance in the telecommunications sector. It is carried out as a case study, exploratory and it has a practical nature. Using a qualitative-quantitative approach and as instruments for the data collecting we used semi-structured interviews with the Project Manager 
responsible for the investment management process. The intervention instrument used was the MCDA-C. This methodology allows us to: identify, organize, measure and integrate the criteria. The built model enables the company's manager to view the process profile in the criteria identified as important to the success of his organization. The work illustrates for one of the outsourced companies: the impact profile; numeric result for its assessment; the available process using the modeling to generate alternatives to improve the outsourced company's performance, and enabling the manager to understand the consequences of these actions. As a result of this work, it was identified five actions that, according to the perception of the authors allow the performance improvement of both Elementary Point of View (PVEs) Funding Announcement and Target Customers that have the greatest potential for improvement, enabling a higher performance of Fundamental Point of View (PVF) Customers from +27 to +52 .

Keywords: performance assessment, decision aid, energy efficiency, industry

\section{Referências}

AZEVEDO, J. Aplicação da metodologia multicritério de apoio à decisão na seleção de centros de usinagem para uma central de usinagem. 2001. 274 f. Dissertação (Mestrado em Engenharia de Produção) - Programa de PósGraduação em Engenharia de Produção, Universidade Federal de Santa Catarina, Florianópolis, 2001.

cross ref

BANA E COSTA, C. A. Readings in Multicriteria Decision Aid. Springer-Verlag, Berlin, 1990.

BANA E COSTA, C. A. Três convicções fundamentais na prática do apoio à decisão. Pesquisa Operacional, v.13, p. $1-12,1993$.

BANA E COSTA, C. A.; BEINAT, E. Model-structuring in Public Decision-aiding. Working paper LSE OR 05-79, London School of Economics, London, 2005.

BANA E COSTA, C. A.; DE CORTE, J.M.; VANSNICK, J.C. On the mathematical foundations of macbeth. In: Multicriteria Decision Analysis: state of the art survey [edited by Greco, J. F. \& Ehrgott, S. M.], Springer Verlag, Boston, Dordrecht, London, p. 409-442, 2005.

BANA E COSTA, C. A.; ENSSLIN, L.; CORRÊA, É. C.; VANSNICK, J. C. Decision support systems in action: integrated application in a multicriteria decision aid process. European Journal of Operational Research, v. 113, p. 315-335, 1999.

cross ref

BANA E COSTA, C. A.; LOURENÇO, J. C.; CHAGAS, M. P.; BANA E COSTA, J. C. Development of reusable bid evaluation models for the portuguese electric transmission company. Decision Analysis, v. 5, p. 22-42, 2008.

cross ref

BANA E COSTA, C. A.; STEWARD, T.; VANSNICK, J.C. Multicriteria Decision Analysis: some thought based on the tutorial and discussion sessions of the esigma meetings. Proceedings of the EURO XIV Conference, Jerusalem, 3-6 July, 1995.

BANA E COSTA, C. A.; VANSNICK, J. C. Uma nova abordagem ao problema da construção de uma função de valor cardinal: MACBETH. Investigação Operacional, v. 15, p. 15-35.

BARZILAI, J. On the Foundations of Measurement. Proceedings of the 2001 IEEE International Conference on Systems, Man and Cybernetics, Tucson, p.7-10, 2001.

BOSSEBOEUF, D.; CHATEAU, B.; LAPILLONNE, B. Cross-country comparison on energy efficiency indicators: the on-going European effort towards a common methodology. Energy Policy, v. 25, n. 7-9, p. 673-682, 1997.

cross ref 
CAMPOS, V. R.; ALMEIDA, A. T. Modelo multicritério de decisão para localização de nova jaguaribara com vip analysis. Pesquisa Operacional, v. 26, p. 91-107, 2006.

cross ref

CHEN, Y.; KILGOUR, D. M.; HIPEL, K. W. A case-based distance method for screening in multiple-criteria decision aid. Omega, v.36, p. 373-383, 2008.

cross ref

CORREA, E. C. Construção de um modelo multicritério de apoio ao processo decisório. 2006. Dissertação (Mestrado em Engenharia de Produção) - Programa de Pós-Graduação em Engenharia de Produção, Universidade Federal de Santa Catarina, Florianópolis, 2006.

DVIR, D.; LIPOVETSKY, S.; SHENHAR, A.; TISHLER, A. In search of project classification: a non-universal approach to project success factors. Research Policy, v. 27, p. 915-935, 1998.

cross ref

EDEN, C.; ACKERMANN, F. The analysis of cause maps. Journal of Management Studies, v.29, p. 309-324, 1992. cross ref

ENSSLIN, L.; DUTRA, A.; ENSSLIN, S. R. MCDA: a construtivist approach to the management of human resources at a governmental agency. International Transactions in Operational Research, v.7, p.79-100, 2000.

cross ref

ENSSLIN, L.; GIFFHORN, E.; ENSSLIN, S. R.; PETRI, S. M.; VIANNA, W. B. Avaliação do Desempenho de Empresas Terceirizadas com o Uso da Metodologia Multicritério de Apoio à Decisão- Construtivista. Revista Pesquisa Operacional, v.30, n. 1, p. 125 - 152, 2010.

ENSSLIN, L.; LONGARAY, A. A.; MACKNESS, J. R. (2005). Decision Support System to Aid a Patient with Stress to Identify Opportunities to Improve her Quality of Life. Proceedings of the Annual International Scientific Conference Operations Research, p.7-9, Bremen, 2005.

ENSSlin, L.; MONTIBELleR, G. N.; NORONHA, S. M. Apoio à Decisão: Metodologias para Estruturação de Problemas e Avaliação Multicritério de Alternativas. Insular, Florianópolis, 2001.

EPE - Empresa de Pesquisa Energética. NOTA TÉCNICA DEA 14/10. Análise da eficiência energética na indústria e nas residências no horizonte decenal (2010-2019). 2010.

GOMES, C. F. S. Using MCDA methods THOR in an application for outranking the ballast water management options. Pesquisa Operacional, v. 25, p. 11-28, 2005.

cross ref

GOODWIN, P.; WRIGHT, G. Decision Analysis for Management Judgment. John Wiley \& Sons, Chichester, 1998.

HAYS, R. H.; PISANO, P.G. Beyond world-class: the new manufacturing strategies. Harvard Business Review, v.72, p.77-86, 1994.

HEIJDEN, K. V. D. Scenarios: The Art of Strategic Conversation. John Wiley \& Sons, Chichester, 1996.

IBGE. (2007) Instituto Brasileiro de Geografia e Estatística. Disponível em: <http://www.ibge.gov.br/estadosat/perfil. php?sigla=sc >. Acesso em Maio de 2007.

IEA. World Energy Outlook 2006. Paris: International Energy Agency, 2006.

IGARASHI, D. C. C.; ENSSLIN, S. R.; ENSSLIN, L.; PALADINI, E. P. A qualidade do ensino sob o viés da avaliação de um programa de pós-graduação em contabilidade: proposta de estruturação de um modelo híbrido. Revista de Gestão USP, v. 43, p. 117-137, 2008.

JANNUZZI, G. M. Políticas públicas para eficiência energética e energia renovável no novo contexto de mercado: uma análise da experiência recente dos EUA e do Brasil. Campinas, SP: Autores Associados, 2000. 
JANUZZI, G.M.; GOMES, R.D. A experiência brasileira pós-privatização em programas de eficiência energética e P\&D: lições das iniciativas de regulação e da crise energética.Campinas, 2009.

KEENEY, R. L. Value-focused thinking: a path to creative decisionmaking. Harvard University Press, London, 1992.

KEENEY, R. L.; RAIFFA, H. Decisions with Multiple Objectives: Preferences and Value Trade-offs. Wiley, New York, 1976.

LANDRY, M. A note on the concept of problem. Organization Studies, v.16, p.315-343, 1995.

$$
\text { cross ref }
$$

LANDRY, M.; PASCOT, D.; BRIOLAT, D. Can DSS evolve without changing our view of the concept of 'problem'? Decision Support Systems, v.1, p.25-36, 1985.

\section{cross ${ }^{\text {ref }}$}

LONGARAY, A. A.; ENSSLIN, L.; MACKNESS, J. Use of Constructivist Multi-criteria Decision Aid Model with Soft Systems Methodology to Improve the Quality of Life of a Patient with Stress. Proceedings of the International Scientific Congress of Operations Research, Bremen, p. 234-235, 2005.

LOVINS, A.; SWISHER, J. “Clean Energy for a Sustainable Brazil”. In: Seminário Diálogos para um desenvolvimento sustentável. Rocky Mountain Institute, 19 May 2003.

MCLEAN-CONNER, P. Energy Efficiency: Principles and Practices. Tulsa, Oklahoma (EUA) : PennWell Corporation, p. 194, 2009.

MME - Ministério das Minas e Energia. Balanço Energético Nacional. Brasília, 2005.

MME/FDTE - Fundação para o Desenvolvimento Tecnológico de Engenharia. Balanço de Energia Útil. Brasília: MME/FDTE, 2005.

ORTEGA, B. G. P. Propostas para regulação da eficiência energética nos sistemas elétricos de consumidores. Dissertação. 2006, 90 f. Dissertação (Mestrado em Regulação da Indústria de Energia) - Programa de Pós-Graduação em Engenharia , Universidade Salvador, Salvador, 2006.

PATTERSON, M. G. What is energy efficiency? : Concepts, indicators and methodological issues. Energy Policy, v.24, n.5, p.377-390. 2001.

MUNDA, G. Between science and democracy: the role of "social multi-criteria evaluation (SMCE). European Working Group “Multicriteria Aid for Decisions”, v. 7, n.3, p. 1-5, 2003.

ROY, B. Decision science or decision-aid science? European Journal of Operational Research, v.66, p.184-203, 1993.

\section{cross}

ROY, B. On operational research and decision aid. European Journal of Operational Research, v.73, p.23-26, 1994.

\section{cross ref}

ROY, B. Multicriteria Methodology for Decision Aiding. Kluwer Academic Publishers, Dordrecht, 1996.

\section{cross ref}

ROY, B. Paradigms and Challenges, Multiple Criteria Decision Analysis - State of the Art Survey. In: Multicriteria Decision Analysis: state of the art survey [edited by Greco, J. F. \& Ehrgott, S. M.], Springer Verlag, Boston, Dordrecht, London, p. 03-24, 2005.

ROY, B.; BOUYSSOU, D. Decision-aid: an elementary introduction with emphasis on multiple criteria. Information Science and Technology, v.2, p.109-123, 1993.

ROY, B.; VANDERPOOTEN, D. The european school of MCDA: emergence, basic features and current works. Journal of Multi-Criteria Decision Analysis, v.5, p.22-38, 1996. 
SANNEMANN, G.D.R.; ENSSLIN, L.; ENSSLIN, S.R.; DUTRA, A. Reflections on the Structuring of the Organizational Performance Problem using an MCDA-C Approach from an Integrative Systemic-synergetic Perspective. Proceedings of the 21st European Conference on Operational Research, Iceland, 2006.

SHENHAR, A. J. One size does not fit all projects: exploring classical contingency domains. Management Science, v.47, p.394-414, 2001.

cross ref

SKINNER, W. The productivity paradox. Management Review, v.75, p.41-45, 1986.

STEWARD, T. Dealing with uncertainties in MCDA. In: Multicriteria Decision Analysis: state of the art survey [edited by Greco, J. F. \& Ehrgott, S. M.], Springer Verlag, Boston, Dordrecht, London, p.445-470, 2005.

US Report of the National Policy Development Group. "Using energy wisely. Increasing Energy Conservation and Efficiency". In: Reliable affordable and environmentally sound energy for the American Future. Washington, 2001.

TASCA, J. E. Avaliação do processo de capacitação dos policiais militares instrutores do programa educacional de resistências às drogas - PROERD, em Santa Catarina, por meio da MCDA-C. 2010. 265 f. Dissertação (Mestrado em Engenharia de Produção) - Universidade Federal de Santa Catarina, Florianópolis, 2010.

Visual Thinking International Ltd. V.I.S.A. for Windows Manual, 1995

ZAMBON, K. L.; CARNEIRO, A. A. F. M.; SILVA, A. N. R.; NEGRI, J. C. Análise de decisão multicritério na localização de usinas termoelétricas utilizando SIG. Pesquisa Operacional, v.25, p.183-199, 2005.

cross ref

ZIMMERMANN, H. An application-oriented view of modeling uncertainty. European Journal of Operations Research, v.122, p.190-198, 2000.

\section{cross ref}

\section{Dados dos autores:}

\section{Nome completo: Sandra Rolim Ensslin}

Filiação institucional: Universidade Federal de Santa Catarina - UFSC

Departamento: Departamento de Engenharia de Produção e Sistemas

Função ou cargo ocupado: Professora do Programa de Pós-Graduação em Engenharia de Produção (PPGEP) de Contabilidade (PPGC)

Endereço completo para correspondência: Campus Universitário - Trindade, Caixa Postal 476, CEP 88040-900, Florianópolis, SC, Brasil

Telefones para contato: (55) 48 3721-6608

E-mail: sensslin@gmail.com

Nome completo: Leonardo Ensslin

Filiação institucional: Universidade Federal de Santa Catarina - UFSC

Departamento: Departamento de Engenharia de Produção e Sistemas 
Função ou cargo ocupado: Professor do Programa de Pós-Graduação em Engenharia de Produção (PPGEP) de Contabilidade (PPGC)

Endereço completo para correspondência (bairro, cidade, estado, país e CEP): Campus Universitário - Trindade, Caixa Postal 476, CEP 88040-900, Florianópolis, SC, Brasil

Telefones para contato: (55) 48 3721-7022

E-mail: leonardoensslin@gmail.com

Nome completo: Eduardo Kazumi Yamakawa

Filiação institucional: Universidade Federal de Santa Catarina - UFSC

Departamento: Departamento de Engenharia de Produção e Sistemas

Função ou cargo ocupado: Aluno do Programa de Pós-Graduação em Engenharia de Produção (PPGEP)

Endereço completo para correspondência (bairro, cidade, estado, país e CEP): Campus

Universitário - Trindade, Caixa Postal 476, CEP 88040-900, Florianópolis, SC, Brasil

Telefones para contato: (55) 48 3721-7022

E-mail: eduardo_yamakawa@uol.com.br

Nome completo: Marilda da Penha Teixeira Nagaoka

Filiação institucional: Universidade Federal de Santa Catarina - UFSC

Departamento: Departamento de Engenharia de Produção e Sistemas

Função ou cargo ocupado: Aluna do Programa de Pós-Graduação em Engenharia de Produção (PPGEP)

Endereço completo para correspondência (bairro, cidade, estado, país e CEP): Campus Universitário - Trindade, Caixa Postal 476, CEP 88040-900, Florianópolis, SC, Brasil

Telefones para contato: (55) 48 3721-7022

E-mail: marildanagaoka@yahoo.com.br

Nome completo: Gustavo Klinguelfus

Filiação institucional: Universidade Federal do Paraná - UFPR

Departamento: Departamento de Engenharia de Elétrica

Função ou cargo ocupado: Aluno do Programa de Pós-Graduação em Engenharia Elétrica

Endereço completo para correspondência (bairro, cidade, estado, país e CEP): Centro Politécnico da Universidade Federal do Paraná - Jardim das Américas, Caixa Postal 19067, CEP 81531-980, Curitiba, PR, Brasil

Telefones para contato: (55) 41 3361-6268 


\section{Nome completo: Luciano Cavalcante Siebert}

Filiação institucional: Universidade Federal do Paraná - UFPR

Departamento: Departamento de Engenharia de Elétrica

Função ou cargo ocupado: Aluno do Programa de Pós-Graduação em Engenharia Elétrica

Endereço completo para correspondência (bairro, cidade, estado, país e CEP): Centro Politécnico da Universidade Federal do Paraná - Jardim das Américas, Caixa Postal 19067, CEP 81531-980, Curitiba, PR, Brasil

Telefones para contato: (55) 41 3361-6268

E-mail: siebert.luciano@gmail.com

\section{Nome completo: Alexandre Rasi Aoki}

Filiação institucional: Universidade Federal do Paraná - UFPR

Departamento: Departamento de Engenharia de Elétrica

Função ou cargo ocupado: Professor do Programa de Pós-Graduação em Engenharia Elétrica

Endereço completo para correspondência (bairro, cidade, estado, país e CEP): Centro Politécnico da Universidade Federal do Paraná - Jardim das Américas, Caixa Postal 19067, CEP 81531-980, Curitiba, PR, Brasil

Telefones para contato: (55) 41 3361-6012

E-mail: araoki@gmail.com

\section{Enviado em: 04/10/2011}

Aprovado em: 06/02/2013 